\title{
Chemical evolution of volatile organic compounds in the outflow of the Mexico City Metropolitan area
}

\author{
E. C. Apel ${ }^{1}$, L. K. Emmons ${ }^{1}$, T. Karl ${ }^{1}$, F. Flocke ${ }^{1}$, A. J. Hills ${ }^{1}$, S. Madronich ${ }^{1}$, J. Lee-Taylor ${ }^{1}$, A. Fried ${ }^{1}$, P. Weibring ${ }^{1}$, \\ J. Walega ${ }^{1}$, D. Richter ${ }^{1}$, X. Tie ${ }^{1}$, L. Mauldin ${ }^{1}$, T. Campos ${ }^{1}$, A. Weinheimer ${ }^{1}$, D. Knapp ${ }^{1}$, B. Sive ${ }^{2}$, L. Kleinman ${ }^{3}$, \\ S. Springston ${ }^{3}$, R. Zaveri ${ }^{4}$, J. Ortega ${ }^{4,}$, P. Voss $^{5}$, D. Blake ${ }^{6}$, A. Baker ${ }^{6}$, C. Warneke ${ }^{7}$, D. Welsh-Bon ${ }^{7}$, J. de Gouw ${ }^{7}$, \\ J. Zheng ${ }^{8}$, R. Zhang ${ }^{8}$, J. Rudolph ${ }^{9}$, W. Junkermann ${ }^{10}$, and D. D. Riemer ${ }^{11}$ \\ ${ }^{1}$ National Center for Atmospheric Research, Boulder, CO, USA \\ ${ }^{2}$ University of New Hampshire, Durham, NH, USA \\ ${ }^{3}$ Brookhaven National Laboratory, Upton, NY, USA \\ ${ }^{4}$ Pacific Northwest National Laboratory, Richland, WA, USA \\ ${ }^{5}$ Smith College and the University of Massachusetts, Amherst, MA, USA \\ ${ }^{6}$ University of California, Irvine, CA, USA \\ ${ }^{7}$ National Oceanic and Atmospheric Administration, Boulder, CO, USA \\ ${ }^{8}$ Department of Atmospheric Sciences, Texas A\&M, College Station, TX, USA \\ ${ }^{9}$ York University, Toronto, Ontario, Canada \\ ${ }^{10}$ Institute for Meteorology and Climate Research, IMK-IFU, Research Center Karlsruhe, Garmisch-Partenkirchen, Germany \\ ${ }^{11}$ University of Miami, Rosenstiel School of Marine and Atmospheric Sciences, Miami, FL, USA \\ * currently at: the National Center for Atmospheric Research, Boulder, CO, USA
}

Received: 07 October 2009 - Published in Atmos. Chem. Phys. Discuss.: 12 November 2009

Revised: 12 February 2010 - Accepted: 20 February 2010 - Published: 8 March 2010

\begin{abstract}
The volatile organic compound (VOC) distribution in the Mexico City Metropolitan Area (MCMA) and its evolution as it is uplifted and transported out of the MCMA basin was studied during the 2006 MILAGRO/MIRAGEMex field campaign. The results show that in the morning hours in the city center, the VOC distribution is dominated by non-methane hydrocarbons (NMHCs) but with a substantial contribution from oxygenated volatile organic compounds (OVOCs), predominantly from primary emissions. Alkanes account for a large part of the NMHC distribution in terms of mixing ratios. In terms of reactivity, NMHCs also dominate overall, especially in the morning hours. However, in the afternoon, as the boundary layer lifts and air is mixed and aged within the basin, the distribution changes as secondary products are formed. The WRF-Chem (Weather Research and Forecasting with Chemistry) model and MOZART (Model for Ozone and Related chemical Tracers) were able to approximate the observed MCMA daytime patterns and ab-
\end{abstract}

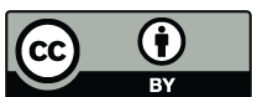

Correspondence to: E. C. Apel (apel@ucar.edu) solute values of the VOC OH reactivity. The MOZART model is also in agreement with observations showing that NMHCs dominate the reactivity distribution except in the afternoon hours. The WRF-Chem and MOZART models showed higher reactivity than the experimental data during the nighttime cycle, perhaps indicating problems with the modeled nighttime boundary layer height.

A northeast transport event was studied in which air originating in the MCMA was intercepted aloft with the Department of Energy (DOE) G1 on 18 March and downwind with the National Center for Atmospheric Research (NCAR) C130 one day later on 19 March. A number of identical species measured aboard each aircraft gave insight into the chemical evolution of the plume as it aged and was transported as far as $1000 \mathrm{~km}$ downwind; ozone was shown to be photochemically produced in the plume. The WRF-Chem and MOZART models were used to examine the spatial extent and temporal evolution of the plume and to help interpret the observed $\mathrm{OH}$ reactivity. The model results generally showed good agreement with experimental results for the total $\mathrm{VOC} \mathrm{OH}$ reactivity downwind and gave insight into the distributions of VOC chemical classes. A box model with

Published by Copernicus Publications on behalf of the European Geosciences Union. 
detailed gas phase chemistry (NCAR Master Mechanism), initialized with concentrations observed at one of the ground sites in the MCMA, was used to examine the expected evolution of specific VOCs over a 1-2 day period. The models clearly supported the experimental evidence for NMHC oxidation leading to the formation of OVOCs downwind, which then become the primary fuel for ozone production far away from the MCMA.

\section{Introduction}

The influence of large urban centers on regional atmospheres is a topic of increasing interest to the atmospheric science community as the number of megacities (cities with populations $>10$ million people) continues to grow. Mexico City is a megacity that has continued to grow in both population and area and is one of the largest cities in the world. Numerous studies have reported (e.g., Molina and Molina, 2002) on both the current status of air quality in the Mexico City Metropolitan Area (MCMA) and on more fully understanding the root causes of air pollution in the area. Although lagging most US and European cities, MCMA has implemented new technologies to help improve air quality; overall, air quality has improved over the last decade even though very high emissions of ozone precursors, nitrogen oxides $\left(\mathrm{NO}_{\mathrm{x}}\right)$ and VOCs, as well as primary particulate matter (PM) remain (Molina and Molina, 2002). Fewer studies have looked at the outflow from the city in terms of spatial extent and temporal evolution. This is of topical interest since the export of pollutants from megacities and concentrated urban centers to downwind areas is of growing concern and has led to an awareness that regional areas may be impacted by this outflow and that urban centers downwind may experience significantly greater challenges with their air pollution mitigation strategies because of the importation of pollutants. This can also happen on inter-continental spatial scales. A prime example is in the western United States where concern has heightened over pollutants being transported across the Pacific from the rapidly industrializing Asian subcontinent (e.g., Jacob et al., 2003; Parrish et al., 2004).

Tracking the export of pollutants and understanding the impact of large urban centers on downwind air quality is scientifically challenging and requires a synthesis of observational data and modeling results. The MIRAGE-Mex field experiment was designed to characterize the chemical and physical transformations and the ultimate fate of pollutants exported from the MCMA, and was part of the MILAGRO group of field campaigns. An overview of the field campaign is given by Molina et al. $(2008,2010)$. The MCMA, located in an elevated basin, is relatively isolated from other large urban centers and, in this respect, can be considered a pollution point source, making it a good candidate for this study. A combination of ground-based experiments, aircraft exper- iments with different but overlapping spatial coverage and instrument payloads, and zero-dimensional, regional, and global models were used to investigate plumes as they exited the MCMA and evolved in space and time. This evolution involves significant chemical transformations which, in turn, require instrumentation capable of measuring the secondary products that result from atmospheric processing. To track the outflow it is necessary to first quantify the composition of air in the MCMA basin. This was done with a network of three instrumented sites set up along the statistically most significant outflow path: T0, located approximately $11 \mathrm{~km}$ miles north-northeast of downtown Mexico City; T1, located approximately $32 \mathrm{~km}$ northeast of $\mathrm{T} 0$; and $\mathrm{T} 2$, located approximately $64 \mathrm{~km}$ northeast of the city. For the analysis presented here, we take advantage of measurements from $\mathrm{T} 0$ and $\mathrm{T} 1$, sites that were heavily instrumented for tracegas analysis as well as from the DOE G1 aircraft, which repeatedly sampled MCMA air aloft, and the NCAR C130 aircraft which made measurements over the MCMA and up to $1000 \mathrm{~km}$ downwind of the city. Figure 1 (top panel) shows all of the flight tracks taken by the $\mathrm{C} 130$ during the experiment with the 19 March flight shown in green as it will be highlighted in the discussion section. There were a number of flights in which the $\mathrm{C} 130$ flew over the city including the $\mathrm{T} 0, \mathrm{~T} 1$, and $\mathrm{T} 2$ ground stations and these are shown in the lower panel of Fig. 1. A box is drawn around the area that is defined in this paper as the MCMA for over-flight analyses.

In this paper we focus specifically on the characterization of volatile organic compounds (VOCs) in the MCMA, both on the ground and aloft and on the emission, transport, and transformation of VOCs downwind of the metropolitan area. Measurable VOCs as defined here consist of non-methane hydrocarbons (NMHCs) and oxygenated volatile organic compounds (OVOCs), including formaldehyde. NMHCs have primary anthropogenic emission sources which can include evaporative emissions, exhaust, industrial, liquefied petroleum gas, and biomass burning. Sources of OVOCs include primary anthropogenic emissions, primary biogenic emissions, biomass burning, and secondary photochemical formation from both anthropogenic and biogenic sources. Measurements of numerous VOCs on the ground and from the $\mathrm{C} 130$ and $\mathrm{G} 1$ were used to characterize the initial emission conditions, fingerprint the signature of MCMA plumes, and follow the plumes in space and time.

The regional model, WRF with tracers, and the global chemical transport model, MOZART (Emmons et al., 2010a), were used during the experiment to aid in the flight planning, to locate plumes and to help determine when and where the various aircraft would intercept the plumes. Postexperiment, WRF-Chem (Grell et al., 2005; Tie et al., 2009), and MOZART were used to characterize the air masses as they were transported from the MCMA and, at times, encountered by the aircraft, in which case comparisons between the measurements and models could be made. A photochemical 0-D box model, the NCAR Master Mechanism 

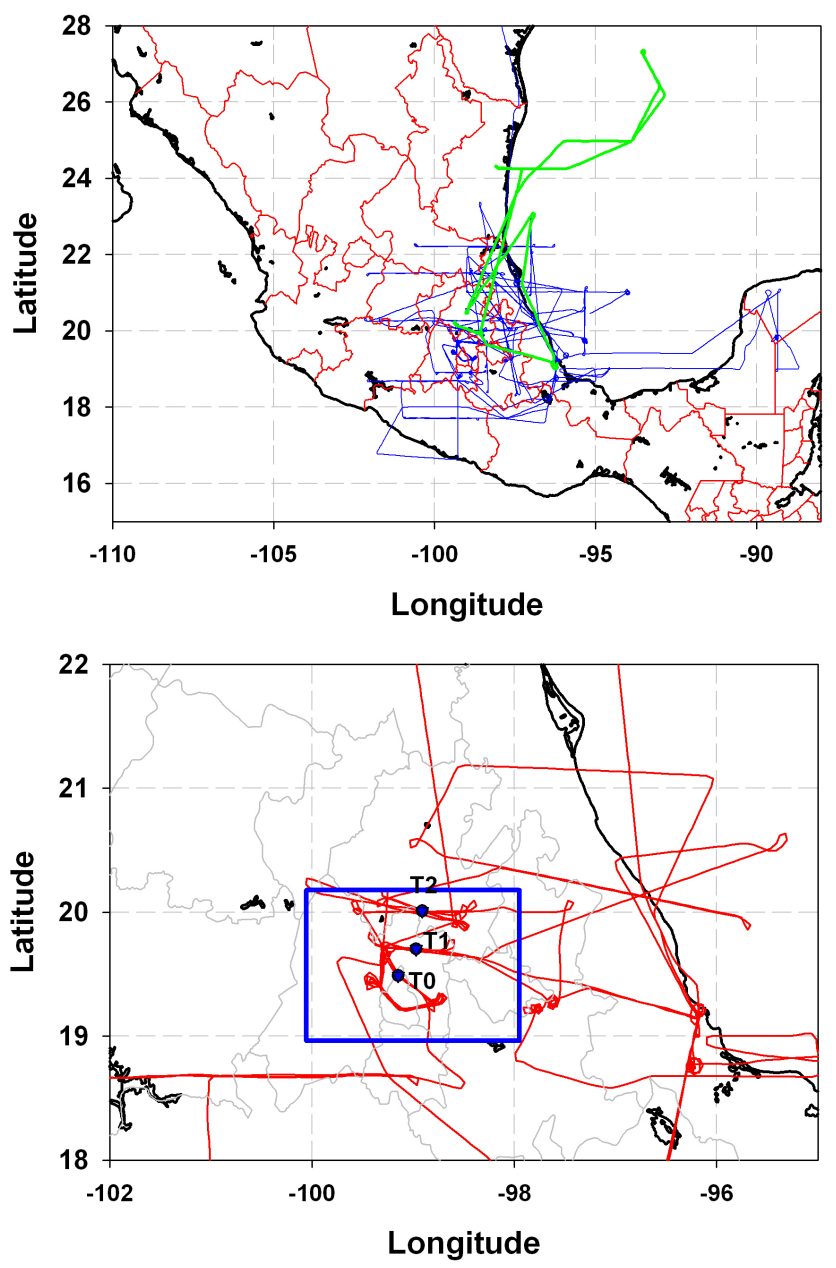

Fig. 1. (top panel) Map of Mexico and the flight tracks taken by the NCAR C130 during the experiment. The flight track for the 19 March outflow event is shown in green. (bottom panel) Map showing the T0, T1 and T2 sampling sites, the box (outlined in blue) showing the MCMA as defined in this paper for over-flight analyses and the flight tracks (red) that passed through the box.

(Madronich, 2006) initialized by ground-based measurements, was used to help interpret observed product VOC species downwind. The transformation of VOCs from primary to secondary species and its impact on the reactivity of the VOC mix downwind is discussed.

An important concept in this paper is the "OH reactivity" (or OH loss rate) provided by individual and classes of VOC species. This will be used to help understand the chemical transformation of air parcels as they are exported out of and downwind of the MCMA. For organic compounds the VOC $+\mathrm{OH}$ reaction initiates the oxidation sequence producing organic peroxy radicals, shown here for alkanes,

$\mathrm{RH}+\mathrm{OH}+\mathrm{O}_{2} \rightarrow \mathrm{RO}_{2}+\mathrm{H}_{2} \mathrm{O}$

where RH represents a VOC with abstractable hydrogen to produce water and an alkyl peroxy radical. Next, the alkyl peroxy radical may react with NO when present,

$\mathrm{RO}_{2}+\mathrm{NO} \rightarrow \mathrm{RO}+\mathrm{NO}_{2}$

to produce an alkoxy radical that reacts with $\mathrm{O}_{2}$,

$\mathrm{RO}+\mathrm{O}_{2} \rightarrow$ carbonyls $+\mathrm{HO}_{2}$

Alternatively, under low $\mathrm{NO}_{\mathrm{x}}$ conditions, the peroxy radicals may react with each other to produce species that may be water-soluble, form aerosols or further react with $\mathrm{OH}$. These conditions were rarely experienced during this study. Ozone production scales with $\mathrm{OH}$ reactivity when $\mathrm{NO}_{\mathrm{x}}$ is elevated. Reaction (R1) represents a major sink term for $\mathrm{OH}$ radicals in the atmosphere. The overall sink term is estimated by calculating $\mathrm{OH}$ loss frequencies (product of concentration and rate coefficient) for all individually measured species,

$\sum_{i}^{n} k_{\left(\mathrm{VOC}_{i}+\mathrm{OH}\right)}\left[\mathrm{VOC}_{i}\right]$

which gives the $\mathrm{OH}$ reactivity, the term used in this paper. The ability of models to reproduce the $\mathrm{OH}$ reactivity is an important step in predicting ozone production (Stroud et al., 2008; Tie et al., 2009). Carbon monoxide (CO) and nitrogen dioxide $\left(\mathrm{NO}_{2}\right)$, and to a smaller extent methane $\left(\mathrm{CH}_{4}\right)$ are also contributors to the $\mathrm{OH}$ loss rate, especially in the city. $\mathrm{CO}$ will be discussed in this context.

\section{Experimental technique}

\subsection{Measurements overview}

A number of coordinated ground-based and aircraft-based experiments were conducted in March of 2006. As mentioned in the introduction, aircraft measurements from the NCAR C130 and the DOE G1 are used as well as groundbased VOC measurements from the T0 site (city center) and the T1 site (outside city center and to the northeast). The geographical location and coverage by aircraft are shown in Fig. 1.

For the C-130 aircraft, a total of 12 flights took place between 4 and 29 March. Two flights (10 and 11) were short flights of three hours duration, while the others were approximately eight hours. Some of the flights were designed to fly over remote regions either to detect long-range plume transport (more than $1000 \mathrm{~km}$ from the Mexico City) or to measure biomass fire plumes. Figure 1 (top panel) shows a map of Mexico with all of the C-130 flight paths superimposed. For this paper, we selected flights in which the flight paths crossed over Mexico City and/or intercepted plumes downwind (northeast) of the city. Flight 7 (19 March, shown in green) will be discussed in the context of transport of the Mexico City plume. Figure 1 (lower panel) shows paths taken for the three research flights that crossed over the 
city. Measurements of VOCs were made on the $\mathrm{C} 130$ with three methods: canister collection for subsequent analysis in the laboratory, proton transfer mass spectrometry (PTRMS), and the Trace Organic Gas Analyzer (TOGA), an insitu gas chromatograph/mass spectrometer (GC-MS). The canister measurements were made by the UC Irvine group and included a full suite of NMHC, organic nitrates, and halogenated species. The NCAR TOGA instrument continuously measured every $2.8 \mathrm{~min} 32$ species including select NMHCs, halogenated compounds, and monofunctional non-acid OVOCs. The NCAR PTR-MS targeted 12 ions and included aromatics and OVOCs. Combined, good coverage was obtained but, for most VOC species, at lower time resolution than is available for continuous measurements for species such as $\mathrm{O}_{3}, \mathrm{NO}_{\mathrm{x}}, \mathrm{CO}$, etc. The TOGA measurements for OVOCs were used in this analysis. Formaldehyde was continuously measured on the C-130 with a Difference Frequency Generation Absorption Spectrometer (DFGAS) (Weibring et al., 2007).

The C-130 MCMA over-flights were used to characterize the VOC emission signatures aloft. In addition, the C-130 intercepted a plume on 19 March that had been sampled a day earlier by the G1. This was a NE transport event at high altitude (4-5.2 km). Air with one to two day transport time from the source was sampled (Voss et al., 2010). As in all flights, a full suite of physical measurements was obtained. A comprehensive suite of trace gas and aerosol data was also obtained on both the $\mathrm{C} 130$ and $\mathrm{G} 1$ aircraft at varying frequencies, with the fastest measurements taken at $1 \mathrm{~Hz}$, e.g., $\mathrm{O}_{3}, \mathrm{CO}, \mathrm{NO}$, $\mathrm{NO}_{2}$, and $\mathrm{NO}_{\mathrm{y}}$. The $\mathrm{C} 130$ and DC-8 flight data are archived at http://www-air.larc.nasa.gov/cgi-bin/arcstat-b. The G1 flight data are archived at ftp://ftp.asd.bnl.gov/pub/ASP\% 20Field\%20Programs/2006MAXMex/.

\subsection{Specific VOC measurements}

\subsubsection{Ground-based measurements}

Canister measurements conducted by the University of California, Irvine (UCI) were used to characterize the NMHCs at the T0 and T1 sites. Air samples were collected in previously evacuated canisters. At T0, individual canisters were filled to $350-700 \mathrm{hPa}$ over $30-60 \mathrm{~min}$ with variable sampling times; a total of 200 canisters were collected. At T1, canisters were filled to $1000 \mathrm{hPa}$ with the sampling time centered at midnight, 3 a.m., 6 a.m., etc.; a total of 200 canisters were collected. Flow was controlled during sample collection with a mass flow controller at both sites. After collection, the canisters were transported back to the UCI laboratory and analyzed for more than 50 trace gases comprising hydrocarbons, halocarbons, dimethyl sulfide (DMS), and alkyl nitrates. In brief, each sample of $1520 \pm 1 \mathrm{~cm}^{3}$ (STP) of air was preconcentrated in a trap cooled with liquid nitrogen, the trap was then warmed by $\sim 80^{\circ} \mathrm{C}$ water, releasing the VOCs into the carrier flow where it was split into six streams, each stream being directed to a different gas chromatograph with a specific column and detector combination. The sample contacts only stainless steel from the sample canister to the 6port splitter and is connected to the columns via Silcosteel ${ }^{\circledR}$ tubing $(0.53 \mathrm{~mm}$ O.D.; Restek Corporation). The columns are all cryogenically cooled during injection and then follow prescribed temperature ramp programs. The sample split is highly reproducible as long as the specific humidity of the injected air is above a certain level, estimated to be $2 \mathrm{~g}$ $\mathrm{H}_{2} \mathrm{O} / \mathrm{kg}$ air. This was ensured by adding $\sim 2.4 \mathrm{kPa}$ of water into each evacuated canister just before they were sent out to the field. The low molecular weight NMHCs were separated by a $\mathrm{J} \& \mathrm{~W}$ Scientific $\mathrm{Al}_{2} \mathrm{O}_{3}$ PLOT column $(30 \mathrm{~m}, 0.53 \mathrm{~mm})$ connected to a flame ionization detector (FID). The detection limit of each NMHC is 1 pptv. All NMHCs were calibrated against whole air working standards, which had been calibrated against NIST and Scott Specialty Gases standards. The precision of the $\mathrm{C}_{2}-\mathrm{C}_{4} \mathrm{NMHC}$ analysis was $\pm 3 \%$ when compared to NIST standards during the Non-Methane Hydrocarbon Intercomparison Experiment (NOMHICE) (Apel et al., 1994, 1999). Further details are given by Colman et al. (2001).

Continuous measurements of 38 masses associated with VOCs were made at the T0 site by the Texas A\&M PTRMS from 5 to 31 March (except from the 23rd through the 26th). The measurements from this group discussed here are acetaldehyde, methanol, acetone, and methyl ethyl ketone (MEK). The T0 measurements were made on the rooftop of a five-story building. A detailed description of the instrument and measurement procedures has been provided by Fortner et al. (2009). A 14 -ft 0.25 -in OD PFA tubing was used as the inlet (5-ft above the roof surface) through which about 30 SLPM sample flow was maintained by a diaphragm pump. During operation, the drift tube pressure was maintained at 2.1 millibars and an $E / N$ ratio of 115 Townsend $\left(1 \mathrm{Td}=10^{17} \mathrm{~V} \mathrm{~cm}^{2}\right.$ molecule $\left.{ }^{-1}\right)$ was utilized. Each of the masses was monitored for $2 \mathrm{~s}$ and it took approximately two min to complete one selected ion monitoring (SIM) scan. Backgrounds were checked for $\sim 15 \mathrm{~min}$ every three hours removing VOCs from the airflow using a custom made catalytic converter. Calibrations were performed daily using commercial standards (Spectra Gases) including alkenes, oxygenated VOCs, and aromatics. The interpretation of mass spectral assignments was based on literature recommendations by de Gouw and Warneke (2007) and Rogers et al. (2006). For species that could not be calibrated onsite, concentrations were determined based on ion-molecular reactions using rate constants reported by Zhao and Zhang (2004).

In addition to the canister measurements of VOCs at T1, on-line continuous measurements were made with a PITMS (Warneke et al., 2005; de Gouw et al., 2009) operated by the National Oceanic and Atmospheric Administration (NOAA). The instrument is similar to a PTR-MS, but uses an ion trap as a mass spectrometer. Measurements for the 
following compounds were utilized in this paper: methanol, acetaldehyde, acetone, and methyl ethyl ketone (MEK). An on-line gas chromatograph with flame ionization detection (GC-FID), operated by NOAA was also used at T1 to measure a number of different hydrocarbon species. In this paper, the UCI canister measurements for NMHCs are used, primarily to ensure consistency between measurements from the T0 andT1 sites. A full description of the T1 VOC measurements, including techniques, is given by de Gouw et al. (2009).

Formaldehyde $\left(\mathrm{CH}_{2} \mathrm{O}\right)$ measurements were made with a modified Aero-Laser AL4001, a commercially available instrument, by the Institute for Meteorology and Climate Research (IMK-IFU, Research Center Karlsruhe, GarmischPartenkirchen). This instrument is based on the Hantzsch technique which is a sensitive wet chemical fluorimetric method that is specific to $\mathrm{CH}_{2} \mathrm{O}$. The transfer of formaldehyde from the gas phase into the liquid phase is accomplished quantitatively by stripping the $\mathrm{CH}_{2} \mathrm{O}$ from the air in a stripping coil with a well defined exchange time between gas and liquid phase. Formaldehyde was measured at two minute time intervals at both the $\mathrm{T} 0$ and $\mathrm{T} 1$ sites. A full description of the instrument and its performance is given in Junkermann and Burger (2006), and an instrumental intercomparison in Hak et al. (2005).

\subsubsection{Aircraft - NCAR C130 and DOE G1}

The analyses of canisters collected on the ground and in the air (C130) are identical. Unlike the ground-based canister sample collection, the aircraft canisters were pressurized to $3500 \mathrm{hPa}$ without using a flow controller which resulted in sample collection times ranging from approximately $30 \mathrm{sec}-$ onds to two min. The number of canisters committed to particular flight legs for individual flights was variable since the total number of canisters available per flight was finite (72). The PTR-MS flown on the $\mathrm{C} 130$ has been thoroughly described in the literature (e.g., Lindinger et al., 1998; de Gouw and Warneke, 2007). For this deployment, 12 ions were targeted for analysis (Karl et al., 2009). These included OVOCs, acetonitrile, benzene, toluene, and C8 and C9 aromatics, as well as the more polar species acetic acid and hydroxyacetone. The measurement frequency was variable but the suite of measurements was typically recorded each minute; during some over-city runs the instrument recorded benzene and toluene measurements at $1 \mathrm{~Hz}$ in order to obtain flux profiling in the MCMA (Karl et al., 2009).

The TOGA instrument has not been previously described in the literature although there are some similarities to a previous version of the instrument which have been documented (Apel et al., 2003). The system is composed of the inlet, cryogenic preconcentrator, gas chromatograph, mass spectrometer, zero air/calibration system, and the data system. All processes and data acquisition are computer controlled. The basic design of the cryogenic preconcentrator is similar to the system described by Apel et al. (2003). Three traps are used; a water trap, an enrichment trap and a cryofocusing trap with no adsorbents in any of the traps. The gas chromatograph (GC) is a custom designed unit that is lightweight and temperature programmable. The GC is fitted with a Restek MTX-624 column (I.D. $=0.18 \mu \mathrm{m}$, length $=8 \mathrm{~m}$ ).

An Agilent 5973 Mass Spectrometer with a fast electronics package was used for detection. A non-standard threestage pumping system was used consisting of a Varian 301 turbomolecular pump, an Adixen (model MDP 5011) molecular drag pump and a DC-motor scroll pump (Air Squared, model V16H30N3.25). The sample volume during this experiment was $33 \mathrm{ml}$. Detection limits were compound dependent but ranged from sub-pptv to $20 \mathrm{pptv}$. The initial GC oven temperature of $30^{\circ} \mathrm{C}$ was held for $10 \mathrm{~s}$ followed by heating to $140^{\circ} \mathrm{C}$ at a rate of $110^{\circ} \mathrm{C} \mathrm{min}^{-1}(60 \mathrm{~s})$. The oven was then immediately cooled to prepare for the next sample. Helium was used as the carrier gas at a flow rate of $1 \mathrm{ml} \mathrm{min}-1$. The system was calibrated with an in-house gravimetrically prepared mixture that had 25 of a targeted 32 compounds. Post-mission calibrations were performed to obtain response factors for the seven compounds not in the standard. The calibration mixture was dynamically diluted with scrubbed ambient (outside aircraft) air to mixing ratios near typically observed levels. A full description of the instrument will be available in a future publication.

The 32 compounds TOGA targeted included OVOC, NMHC, halogenated organic compounds and acetonitrile. Simultaneous measurements were obtained for all compounds every $2.8 \mathrm{~min}$. Measurement comparisons for TOGA and the canister system were excellent for co-measured NMHCs and halogenated VOCs (http://www-air.larc.nasa. gov/cgi-bin/arcstat-b). Agreement between TOGA and the C130 PTR-MS were also generally good (usually within $20 \%$ ) for co-measured species but with greater overall differences than with the canister/TOGA measurements.

The DOE G1 was also equipped with a PTR-MS that measured similar species to the NCAR PTR-MS system. On 18 March, the DOE-G1 and NCAR C-130 flew side-by-side transects over the T1 site (21:15-21:36 UTC) for intercomparison purposes. The two PTR-MS instruments were compared to TOGA showing good agreement for a number of species such as acetone and benzene but discrepancies on the order of 30\% for other species (Ortega et al., 2006). A limited number of canister samples were also collected on the G1 and analyzed for a suite of NMHCs by York University. The York group participated in the NOMHICE program and showed excellent agreement with reference results (Apel et al., 1994, 1999). The majority of the DOE G1 flight hours were carried out in and around the MCMA at altitudes ranging from 2.2 to $5 \mathrm{~km}$. These measurements were used to examine the gas phase and aerosol chemistry above the surface.

Table 1 lists the species, measured from the instruments described above, that were used in the analyses presented here. References to other VOC measurements and complete data sets are given at the bottom of the table. 
Table 1. Measurements from different platforms during MIRAGE$\mathrm{MEX}^{1}$.

\begin{tabular}{|c|c|c|c|c|}
\hline Compound & C-130 & T0 & $\mathrm{T} 1$ & G1 \\
\hline Ethane & UCI & UCI & UCI & York \\
\hline Propane & UCI & UCI & UCI & York \\
\hline i-Butane & TOGA/UCI & UCI & UCI & York \\
\hline n-Butane & TOGA/UCI & UCI & UCI & York \\
\hline i-Pentane & TOGA/UCI & UCI & UCI & York \\
\hline n-Pentane & TOGA/UCI & UCI & UCI & York \\
\hline n-Hexane & UCI & UCI & UCI & York \\
\hline n-Heptane & UCI & UCI & UCI & York \\
\hline n-Octane & UCI & UCI & UCI & York \\
\hline Ethene & UCI & UCI & UCI & York \\
\hline Propene & UCI & UCI & UCI & York \\
\hline 1-Butene & UCI & UCI & UCI & York \\
\hline i-Butene & UCI & UCI & UCI & York \\
\hline trans-2-Butene & UCI & UCI & UCI & York \\
\hline cis-2-Butene & UCI & UCI & UCI & York \\
\hline 1,3-Butadiene & UCI & UCI & UCI & York \\
\hline 1-Pentene & UCI & UCI & UCI & York \\
\hline trans-2-Pentene & UCI & UCI & UCI & York \\
\hline 2-Methyl-2-Butene & UCI & UCI & UCI & York \\
\hline 2-Methyl 1-Propene & UCI & UCI & UCI & York \\
\hline Ethyne & UCI & UCI & UCI & York \\
\hline Benzene & TOGA & UCI & UCI & PNNL \\
\hline Toluene & TOGA/PTR-MS & UCI & UCI & PNNL \\
\hline Ethyl-benzene & TOGA & UCI & UCI & York \\
\hline m-Xylene & TOGA & UCI & UCI & York \\
\hline p-Xylene & TOGA & UCI & UCI & York \\
\hline o-Xylene & TOGA & UCI & UCI & York \\
\hline Xylenes & & & & PNNL \\
\hline Formaldehyde & DFGAS & IMK-IFU & IMK-IFU & \\
\hline Acetaldehyde & TOGA & Texas A\&M & NOAA & PNNL \\
\hline Propanal & TOGA & & & \\
\hline Butanal & TOGA & & & \\
\hline Methanol & TOGA & Texas A\&M & NOAA & PNNL \\
\hline Ethanol & TOGA & & & \\
\hline Acetone & TOGA & Texas A\&M & NOAA & PNNL \\
\hline MEK & TOGA & Texas A\&M & NOAA & PNNL \\
\hline MTBE & TOGA & & & \\
\hline $\mathrm{CO}$ & NCAR & UCI & UCI & $\mathrm{BNL}$ \\
\hline Methane & UCI & UCI & UCI & \\
\hline
\end{tabular}

1 Additional measurements were made of VOCs. For UCI, more complete NMHC measurements are shown in Table 2. For all measurements made at T0 and or T1, please see the archive cdp.ucar.edu. For the G1 VOC measurements please see the archive ftp://ftp.asd.bnl.gov/pub/ASP\%20Field\%20Programs/2006MAXMex/.

\subsection{Models}

An important objective of this study was the intensive use of models of different scales to help interpret the measurements and to study the chemical evolution of the Mexico City plume. Models employed included a regional coupled chemistry-meteorology model (WRF-Chem), a chemical transport model (MOZART-4), and a 0-D chemical box model (NCAR Master Mechanism - MM).

WRF-Chem is a next-generation mesoscale numerical weather prediction system designed to serve both operational forecasting and atmospheric research needs. Modifications to the WRF-Chem chemical scheme specific for this study are described by Tie et al. (2007, 2009). The WRF-Chem version of the model, as used in the present study, includes an on-line calculation of dynamical inputs (winds, temperature, boundary layer, clouds), transport (advective, convec- tive, and diffusive), dry deposition (Wesely et al., 1989), gas phase chemistry, radiation and photolysis rates (Madronich and Flocke, 1999; Tie et al., 2003), and surface emissions including an on-line calculation of biogenic emissions (US EPA Biogenic Emissions Inventory System (BEIS2) inventory). The ozone formation chemistry is represented in the model by the RADM2 (Regional Acid Deposition Model, version 2) gas phase chemical mechanism (Chang et al., 1989) which includes 158 reactions among 36 species. In this study, the model resolution was $6 \times 6 \mathrm{~km}$ in the horizontal direction, in a $900 \times 900 \mathrm{~km}$ domain centered on Mexico City. The model simulation covers 1-30 March 2006.

The chemical scheme of WRF-Chem, RADM2, simplifies the numerous and complex VOC reactions into a relatively smaller set. For example, all potential alkane species (each with different reaction rates) are simplified by using just three alkanes with reaction rate coefficients separated by defined ranges. A single surrogate alkane is used to represent all alkane species that have rate constants with the hydroxyl radical of less than $6.8 \times 10^{-12} \mathrm{~cm}^{3} \mathrm{molec}^{-1} \mathrm{~s}^{-1}$, while alkane species with reaction rate constants greater than this are represented by other surrogate species. The same simplification is done for alkenes, aromatics and OVOCs. For more detail on the emissions and chemical scheme used, see Tie et al. (2009) and references therein.

MOZART-4 (Model for Ozone and Related chemical Tracers, version 4) is a global chemical transport model for the troposphere, driven by meteorological analyses (Emmons et al., 2010a). The results shown here are from a simulation driven by the National Centers for Environmental Prediction (NCEP) Global Forecast System (GFS) meteorological fields (i.e., wind, temperature, surface heat and water fluxes), and have a horizontal resolution of $0.7^{\circ} \times 0.7^{\circ}$, with 42 vertical levels between the surface and $3 \mathrm{hPa}$. Model simulations at $2.8^{\circ} \times 2.8^{\circ}$ starting July 2005 were used to initialize the $0.7^{\circ}$ simulation on 1 March 2006.

The MOZART-4 standard chemical mechanism includes 85 gas-phase species, 12 bulk aerosol compounds that are solved with 39 photolysis and 157 gas-phase kinetic reactions. Lower hydrocarbons and OVOCs are included explicitly (e.g., ethane, ethene, propane, propane, methanol, ethanol, formaldehyde, acetaldehyde), while higher VOCs are represented as a lumped alkane (BIGANE), lumped alkene (BIGENE) and lumped aromatic (TOLUENE). Products of these species (e.g., MEK, higher aldehydes), therefore, are represented as lumped species; modeled acetaldehyde also is a lumped species which includes some contribution from other compounds.

The global emission inventories used in this simulation include the POET (Precursors of Ozone and their Effects in the Troposphere) database for 2000 (Granier et al., 2004) (anthropogenic emissions from fossil fuel and biofuel combustion), and the Global Fire Emissions Database, version 2 (GFED-v2) (van der Werf et al., 2006). The global inventories have been replaced with updated regional estimates for 
Table 2. Mean methane, carbon monoxide and nonmethane hydrocarbon mixing ratios obtained during sampling the month of March 2006. Standard deviations are given in parentheses. T0 and T1 daytime samples were collected between 09:00 and 18:00 local time. The latter two columns show mixing ratios averaged over $24 \mathrm{~h}$ for $\mathrm{T} 0$ and $\mathrm{T} 1$, respectively. Units are pptv except where noted.

\begin{tabular}{|c|c|c|c|c|c|c|c|c|}
\hline \multirow{2}{*}{$\begin{array}{l}\text { Compound } \\
\text { Methane (ppmv) }\end{array}$} & \multicolumn{2}{|c|}{ T0 Day } & \multicolumn{2}{|c|}{ T1 Day } & \multicolumn{2}{|c|}{ T0 24-h } & \multicolumn{2}{|c|}{ T1 24-h } \\
\hline & 2.52 & $(0.97)$ & 1.95 & $(0.17)$ & 2.88 & $(1.14)$ & 2.05 & $(0.26)$ \\
\hline $\mathrm{CO}$ (ppbv) & 1197 & $(908.0)$ & 364 & (199.2) & 1862 & (1351.9) & 500 & $(337.0)$ \\
\hline Ethane & 6447 & $(5728)$ & 2436 & $(1737)$ & 13916 & $(11726)$ & 3001 & $(2637)$ \\
\hline Ethene & 7808 & $(7458)$ & 1894 & $(1681)$ & 13876 & $(11415)$ & 3206 & $(2895)$ \\
\hline Ethyne & 10158 & $(8682)$ & 2597 & $(2163)$ & 16278 & (13 117) & 3688 & (2956) \\
\hline Propane & 37536 & $(34211)$ & 7993 & $(7222)$ & 78341 & (64 263) & 16536 & (19693) \\
\hline Propene & 1765 & $(1961)$ & 484 & $(511)$ & 4005 & $(3580)$ & 1092 & $(1152)$ \\
\hline i-Butane & 8266 & $(10547)$ & 1091 & (954) & 11692 & (9759) & 2105 & (2099) \\
\hline n-Butane & 20332 & (19516) & 3142 & $(2818)$ & 33114 & $(24619)$ & 6093 & $(6084)$ \\
\hline 1-Butene + i-Butene & 1022 & $(1016)$ & 288 & (154) & 1913 & $(1552)$ & 534 & $(456)$ \\
\hline trans-2-Butene & 311 & $(412)$ & 29 & $(30)$ & 497 & $(432)$ & 84 & (98) \\
\hline cis-2-Butene & 330 & $(456)$ & 23 & (28) & 440 & $(407)$ & 57 & (68) \\
\hline i-Pentane & 8380 & (9089) & 910 & $(718)$ & 9244 & (7468) & 1407 & (1150) \\
\hline n-Pentane & 5016 & $(4546)$ & 644 & $(502)$ & 6138 & (4243) & 946 & $(758)$ \\
\hline 1,3-Butadiene & 122 & $(140)$ & 46 & $(31)$ & 327 & $(311)$ & 113 & $(108)$ \\
\hline 1-Pentene & 264 & $(355)$ & 43 & (27) & 291 & $(275)$ & 75 & $(61)$ \\
\hline Isoprene & 134 & $(58)$ & 16 & (19) & 213 & (134) & 49 & (54) \\
\hline trans-2-Pentene & 440 & $(645)$ & 23 & (16) & 540 & $(529)$ & 65 & (65) \\
\hline cis-2-Pentene & 235 & (353) & 21 & (12) & 274 & (279) & 46 & (39) \\
\hline 3-Methyl-1-butene & 126 & (165) & 21 & (14) & 144 & (131) & 35 & (28) \\
\hline 2-Methyl-2-butene & 606 & (864) & 56 & (43) & 748 & (701) & 114 & (114) \\
\hline n-Hexane & 4493 & (6004) & 330 & $(277)$ & 4453 & (4599) & 521 & $(472)$ \\
\hline n-Heptane & 679 & $(707)$ & 109 & (109) & 909 & $(708)$ & 153 & (137) \\
\hline n-Octane & 245 & (197) & 61 & (59) & 302 & $(192)$ & 81 & $(70)$ \\
\hline n-Nonane & 123 & (93) & 35 & (29) & 223 & $(170)$ & 46 & (39) \\
\hline Decane & 224 & (114) & 36 & (26) & 445 & $(328)$ & 43 & (29) \\
\hline 2,2-Dimethylbutane & 656 & $(539)$ & 145 & $(88)$ & 907 & $(621)$ & 195 & $(134)$ \\
\hline 2,3-Dimethylbutane & 2959 & $(2267)$ & 496 & $(388)$ & 4506 & (3098) & 697 & $(584)$ \\
\hline 2-Methylpentane & 2894 & $(2852)$ & 430 & $(304)$ & 3699 & $(2680)$ & 624 & $(458)$ \\
\hline 3-Methylpentane & 2057 & (2057) & 277 & (209) & 2644 & (1945) & 413 & $(318)$ \\
\hline 2,4-Dimethyllpentane & 301 & $(272)$ & 37 & (33) & 440 & $(318)$ & 54 & $(46)$ \\
\hline 2,2,4-Trimethylpentane & 1045 & (1018) & 155 & $(125)$ & 1380 & (1008) & 205 & $(160)$ \\
\hline 2,3,4-Trimethylpentane & 335 & $(324)$ & 57 & $(48)$ & 503 & $(379)$ & 79 & $(68)$ \\
\hline Cyclopentane & 365 & $(320)$ & 54 & (37) & 464 & $(324)$ & 75 & (57) \\
\hline Methylcyclopentane & 960 & $(924)$ & 126 & (103) & 1193 & $(836)$ & 198 & $(165)$ \\
\hline Cyclohexane & 301 & $(217)$ & 68 & $(47)$ & 417 & $(261)$ & 89 & (64) \\
\hline Benzene & 1703 & (1903) & 410 & $(277)$ & 2040 & (1599) & 577 & $(477)$ \\
\hline Toluene & 10649 & (7888) & 1257 & $(1138)$ & 20846 & $(16241)$ & 1875 & $(1565)$ \\
\hline Ethylbenzene & 938 & $(877)$ & 97 & (98) & 1581 & (1312) & 174 & $(182)$ \\
\hline m-Xylene & 845 & (849) & 68 & (80) & 1362 & (1198) & 151 & $(164)$ \\
\hline p-Xylene & 373 & $(402)$ & 29 & (36) & 545 & $(478)$ & 58 & $(65)$ \\
\hline o-Xylene & 404 & $(392)$ & 38 & (46) & 641 & $(529)$ & 77 & (86) \\
\hline iso-Propylbenzene & 40 & $(35)$ & 6 & $(5)$ & 74 & (57) & 10 & (9) \\
\hline n-Propylbenzene & 116 & (103) & 16 & (18) & 236 & (201) & 37 & (49) \\
\hline 3-Ethyltoluene & 244 & $(258)$ & 24 & (24) & 511 & $(445)$ & 52 & $(60)$ \\
\hline 4-Ethyltoluene & 138 & $(142)$ & 14 & (14) & 268 & $(217)$ & 32 & (35) \\
\hline 2-Ethyltoluene & 108 & $(107)$ & 11 & (11) & 187 & $(155)$ & 24 & (28) \\
\hline 1,3,5-Trimethylbenzene & 115 & $(118)$ & 11 & (11) & 295 & $(273)$ & 31 & (39) \\
\hline 1,2,4-Trimethylbenzene & 834 & (869) & 85 & (77) & 1945 & (1707) & 194 & $(236)$ \\
\hline
\end{tabular}


Asia and Mexico. For anthropogenic Asian emissions, the 2006 inventory of Zhang et al. (2009) has been used. The anthropogenic emissions from the Mexico National Emissions Inventory (NEI) for 1999 (http://www.epa.gov/ttn/chief/net/ mexico.html) were used, with gridding to $0.025^{\circ}$ based on population and road locations. Updated inventories exist for MCMA, as summarized by Fast et al. (2009), but were not used in this MOZART simulation. The fire emissions for North America have been replaced by an inventory based on MODIS fire counts with daily time resolution, following Wiedinmyer et al. (2006). See Emmons et al. (2010b) for further details.

The NCAR Master Mechanism is a 0-D model with detailed gas phase chemistry consisting of $\sim 5000$ reactions among $\sim 2000$ chemical species combined with a box model solver. User inputs include but are not limited to species of interest, emissions, temperature, and boundary layer height. This model computes the time-dependent chemical evolution of an air parcel initialized with known composition, assuming no additional emissions, no dilution, and no heterogeneous processes (Madronich, 2006). Any input parameter may be constrained with respect to time. Photolysis rates are calculated using the Tropospheric Ultaviolet-Visible (TUV) model (Madronich and Flocke, 1999), included in the code package.

\section{Discussion and results}

\subsection{MCMA measurements}

\subsubsection{Characterization of VOCs at T1 and To}

Table 2 shows the mean methane, carbon monoxide, and NMHC mixing ratios obtained during March 2006, at T0 and T1 using the UCI canister measurements. The first two columns represent the samples collected between 9:00 and 18:00 local time for $\mathrm{T} 0$ and $\mathrm{T} 1$, respectively. The second two columns show averaged mixing ratios for $\mathrm{T} 0$ and $\mathrm{T} 1$, respectively, over the full $24 \mathrm{~h}$ period. The median [CO] at T1 is about a third of the T0 (CO) with corresponding lower values for the NMHCs at T1 as well. These data along with a more complete data set supplied by UCI were used to derive NMHC abundance and $\mathrm{OH}$ reactivity for the $\mathrm{T} 0$ and $\mathrm{T} 1$ sites. Data from the Texas A\&M PTR-MS (T0) and the NOAA PIT-MS (T1) were used for the OVOC abundance and reactivity (see Table 1).

The daytime data were used to determine ratios of the various NMHCs to $\mathrm{CO}\left([\mathrm{NMHC}]_{\mathrm{pptv}} /[\mathrm{CO}]_{\mathrm{ppbv}}\right)$. Comparing these ratios to other data sets can yield insight into the city emissions. If the correlation between species is high, then an emission ratio can be determined, which can yield further insight into the fuel type used and combustion efficiency, and serve as useful input for developing emission inventories. The first and third columns of Table 3 show the
Table 3. Ratios of NMHCs to CO (ppbv ppmv ${ }^{-1}$ ). The T0 and T1 ratios are from daytime samples between 09:00 and 18:00. The $r^{2}$ value is shown for each ratio obtained at T0 and T1. Emission ratios for US cities are shown for comparison ${ }^{1}$.

\begin{tabular}{|c|c|c|c|c|c|}
\hline \multirow[b]{2}{*}{ Compound } & \multicolumn{2}{|c|}{$\mathrm{T} 0$} & \multicolumn{2}{|c|}{$\mathrm{T} 1$} & \multirow{2}{*}{$\begin{array}{l}\text { US Cities } \\
\text { emission ratio }\end{array}$} \\
\hline & ratio & $r^{2}$ & ratio & $r^{2}$ & \\
\hline Ethane & 7.40 & 0.73 & 3.00 & 0.14 & 2.40 \\
\hline Ethene & 8.40 & 0.99 & 7.90 & 0.85 & 4.10 \\
\hline Ethyne & 9.60 & 0.99 & 8.20 & 0.87 & 3.40 \\
\hline Propane & 41.50 & 0.76 & 49.30 & 0.71 & 3.80 \\
\hline Propene & 2.60 & 0.93 & 2.90 & 0.70 & 1.00 \\
\hline i-Butane & 4.80 & 0.44 & 5.30 & 0.71 & 0.90 \\
\hline n-Butane & 15.10 & 0.69 & 15.30 & 0.71 & 1.40 \\
\hline 1-Butene + i-Butene & 1.10 & 0.88 & 1.20 & 0.72 & 0.38 \\
\hline trans-2-Butene & 0.22 & 0.47 & 0.24 & 0.71 & \\
\hline cis-2-Butene & 0.17 & 0.31 & 0.16 & 0.61 & \\
\hline i-Pentane & 2.70 & 0.24 & 3.20 & 0.89 & 2.90 \\
\hline n-Pentane & 2.10 & 0.46 & 2.10 & 0.84 & 1.20 \\
\hline 1,3-Butadiene & 0.22 & 0.88 & 0.30 & 0.83 & \\
\hline 1-Pentene & 0.08 & 0.16 & 0.12 & 0.57 & \\
\hline Isoprene & 0.08 & 0.71 & 0.11 & 0.50 & \\
\hline trans-2-Pentene & 0.17 & 0.18 & 0.16 & 0.77 & \\
\hline cis-2-Pentene & 0.08 & 0.14 & 0.09 & 0.74 & \\
\hline 3-Methyl-1-butene & 0.04 & 0.20 & 0.05 & 0.37 & \\
\hline 2-Methyl-2-butene & 0.23 & 0.19 & 0.23 & 0.59 & \\
\hline n-Hexane & 1.50 & 0.19 & 1.30 & 0.80 & 0.60 \\
\hline n-Heptane & 0.38 & 0.53 & 0.33 & 0.67 & 0.20 \\
\hline n-Octane & 0.11 & 0.59 & 0.12 & 0.36 & 0.10 \\
\hline n-Nonane & 0.09 & 0.57 & 0.07 & 0.37 & \\
\hline Decane & 0.15 & 0.40 & 0.06 & 0.30 & \\
\hline 2,2-Dimethylbutane & 0.41 & 0.79 & 0.36 & 0.88 & \\
\hline 2,3-Dimethylbutane & 2.20 & 0.92 & 1.40 & 0.70 & \\
\hline 2-Methylpentane & 1.40 & 0.51 & 1.20 & 0.87 & \\
\hline 3-Methylpentane & 1.00 & 0.51 & 0.86 & 0.88 & \\
\hline 2,4-Dimethyllpentane & 0.21 & 0.77 & 0.12 & 0.86 & \\
\hline 2,2,4-Trimethylpentane & 0.59 & 0.63 & 0.41 & 0.81 & \\
\hline 2,3,4-Trimethylpentane & 0.25 & 0.78 & 0.18 & 0.84 & \\
\hline Cyclopentane & 0.18 & 0.59 & 0.15 & 0.86 & \\
\hline Methylcyclopentane & 0.44 & 0.51 & 0.45 & 0.86 & \\
\hline Cyclohexane & 0.18 & 0.84 & 0.16 & 0.77 & \\
\hline Benzene & 0.93 & 0.93 & 1.20 & 0.89 & 0.70 \\
\hline Toluene & 7.50 & 0.63 & 5.20 & 0.88 & 2.70 \\
\hline Ethylbenzene & 0.88 & 0.68 & 0.42 & 0.83 & 0.40 \\
\hline m-Xylene & 0.76 & 0.58 & 0.33 & 0.74 & 0.60 \\
\hline p-Xylene & 0.37 & 0.61 & 0.14 & 0.70 & 0.30 \\
\hline o-Xylene & 0.36 & 0.60 & 0.19 & 0.73 & 0.50 \\
\hline iso-Propylbenzene & 0.04 & 0.79 & 0.02 & 0.58 & \\
\hline n-Propylbenzene & 0.11 & 0.77 & 0.08 & 0.70 & \\
\hline $1,2,4$-Trimethylbenzene & 0.84 & 0.68 & 0.28 & 0.53 & \\
\hline
\end{tabular}

${ }^{1}$ Baker et al. (2008)

([NMHC $\left.]_{\mathrm{pptv}} /[\mathrm{CO}]_{\mathrm{ppbv}}\right)$ data obtained from the canisters at T0 and T1, respectively. The second and fourth columns show the $r^{2}$ values for the T0 and T1 data, respectively. The fifth column shows ratios obtained by averaging values from 28 US cities (Baker et al., 2008). Large differences are evident for some species between the MCMA data and the averaged US city data. It should be noted that ratios of NMHCs to $\mathrm{CO}$ can vary substantially from city to city (Warneke et al., 2007; Baker et al., 2008), particularly for light alkanes. However, in no US city do ratios approach the MCMA 


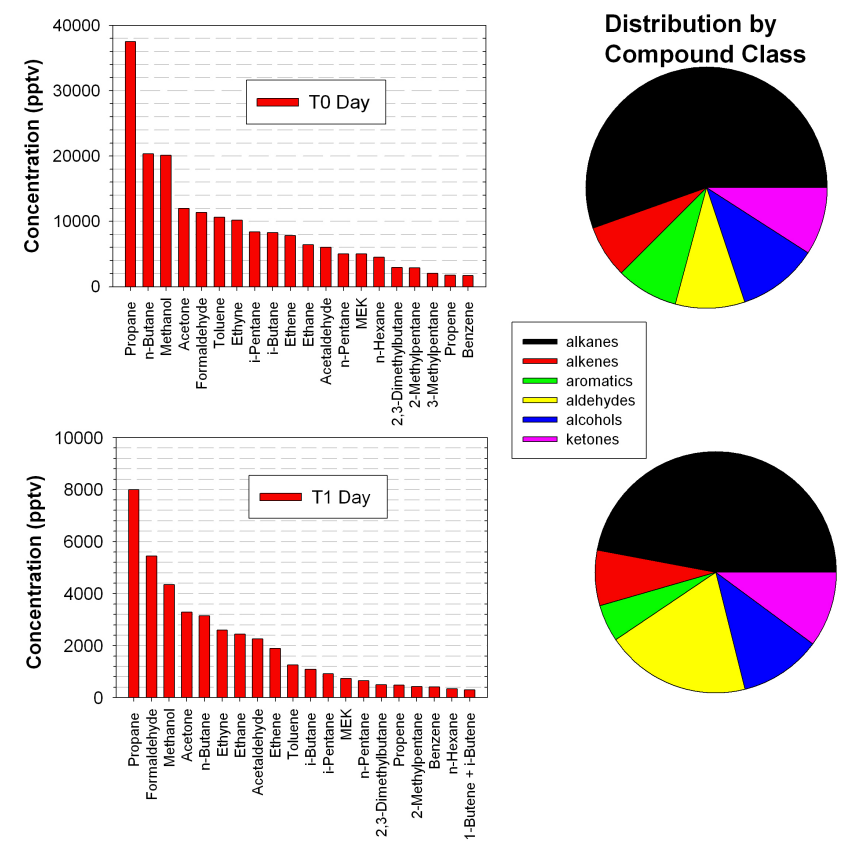

Fig. 2. The top 20 compounds measured at T0 (top panel) and T1 (lower panel) in terms of mixing ratios between 09:00 and 18:00 local time averaged over the month of March 2006. Shown to the right of each bar graph is a breakdown, for T0 and T1, respectively, of all of the species measured in terms of the sums of the mixing ratios for each compound class.

ratios for propane, i-butane, and n-butane. This is most likely attributable to the widespread use of liquid petroleum gas (LPG) in cooking fuel in Mexico City (Blake and Rowland, 1995, Velasco, 2006). Note that the $\mathrm{NMHC/CO}$ ratios at the T0 and T1 sites are very similar for most compounds. Notable exceptions are ethane, toluene, ethyl benzene, and the xylenes with the emission ratios markedly higher at the T0 site, likely due to strong local emissions. The NMHC/CO ratios at both sites for the BTEX (benzene, toluene, ethyl benzene, xylenes) compounds are enhanced relative to vehicle exhaust (Zavela et al., 2006) and indicate significant industrial emissions. Karl et al. (2009) and Fortner et al. (2009) noted that toluene appears to have significant industrial sources within the city that would increase its ratio to CO. There are also significant differences versus US cities (not shown in table), in the ratios of ethene and propene, two highly reactive species, to $\mathrm{CO}$. The most important source of alkenes is believed to be vehicle emissions and differences in combustion efficiencies can contribute to the differences in the ratio (Doskey et al., 1992; Altuzar et al., 2004; Velasco et al., 2005) but LPG and industrial emissions (Fried et al., 2009) can also be important.

For most measured species, a strong diurnal variation was observed with high mixing ratios at night when VOC emissions accumulated in a shallow boundary layer, and lower mixing ratios during the day when VOCs were mixed in a deeper boundary layer and were removed by photochemistry. However, diurnal patterns in VOC measurements were substantially different for oxygenated VOCs, indicative of secondary production occurring from the processing of NMHCs (de Gouw et al., 2009).

Figure 2 graphically shows the 20 most abundant VOCs (NMHCs and OVOCs) as measured at the T0 and T1 sites, top panel and bottom panel, respectively. The measurements for $\mathrm{T} 0$ and $\mathrm{T} 1$ are daytime averaged values obtained between 09:00 and 18:00 local time. For a detailed discussion of the $\mathrm{T} 1$ analysis, including diurnal profiles of select VOC species, please see de Gouw et al. (2009). The bar graphs show the species from left to right in descending order of abundance with the mixing ratios given in pptv on the y-axis. To the right of each bar graph is a pie chart showing the breakdown of the most abundant species summed by compound class. Both the $\mathrm{T} 0$ and $\mathrm{T} 1$ ground sites show high mixing ratios for a number of NMHC and OVOC species. Propane is the most abundant species with an average value over $30 \mathrm{ppbv}$ at T0 and approximately $8 \mathrm{ppbv}$ at T1. Aromatics result from vehicle emissions but are also widely used in paints, and industrial cleaners and solvents. Aldehydes result from fossil fuel combustion and are formed in the atmosphere from the oxidation of primary NMHCs (Atkinson, 1990). The two most prevalent ketones, acetone and methyl ethyl ketone, are believed to have primary sources similar to the aromatic compounds but with a higher fraction of emissions from paints and solvents compared to mobile sources. Secondary sources of these species were found to be large at T1 (de Gouw et al., 2009). Less is known about the emissions of the alcohols. But methanol is one of the most prevalent VOCs with average mixing ratios of approximately $20 \mathrm{ppbv}$ at $\mathrm{T} 0$ and 4 ppbv at T1, during a season when biogenic emissions are believed to be low. Methanol concentrations averaged 50 ppbv during the morning rush hour (Fortner et al., 2009). Strong correlations of methanol with $\mathrm{CO}$ were observed. The aldehydes are present in relatively higher amounts at $\mathrm{T} 1$ versus the T0 site. Biomass burning is also a source for all of the aforementioned VOC species at $\mathrm{T} 0$ or $\mathrm{T} 1$ but is minor relative to mobile and industrial emissions (de Gouw et al., 2009; Karl et al., 2009). There are other OVOC species that were not measured at either one or both the $\mathrm{T} 0$ and $\mathrm{T} 1$ sites in this study and these include but are not limited to methyl tertiary butyl ether (MTBE), a gasoline additive, multifunctional group species such as glyoxal, (Volkamer et al., 2007), methyl glyoxal, ethyl acetate (Fortner et al., 2006) and two of the primary oxidation products of isoprene, methyl vinyl ketone and methacrolein.

Figure 3 displays data in a similar fashion to Fig. 2, but shows the VOC OH reactivity results in bar graphs and pie charts. The bar graphs show the top 20 measured VOC species in terms of their daytime averaged contribution to the $\mathrm{OH}$ reactivity in $\mathrm{s}^{-1}$ (primary y-axis) and percent $\mathrm{OH}$ reactivity (secondary y-axis). The total averaged over-theday reactivity for the measured VOC compounds is $19.7 \mathrm{~s}^{-1}$ 

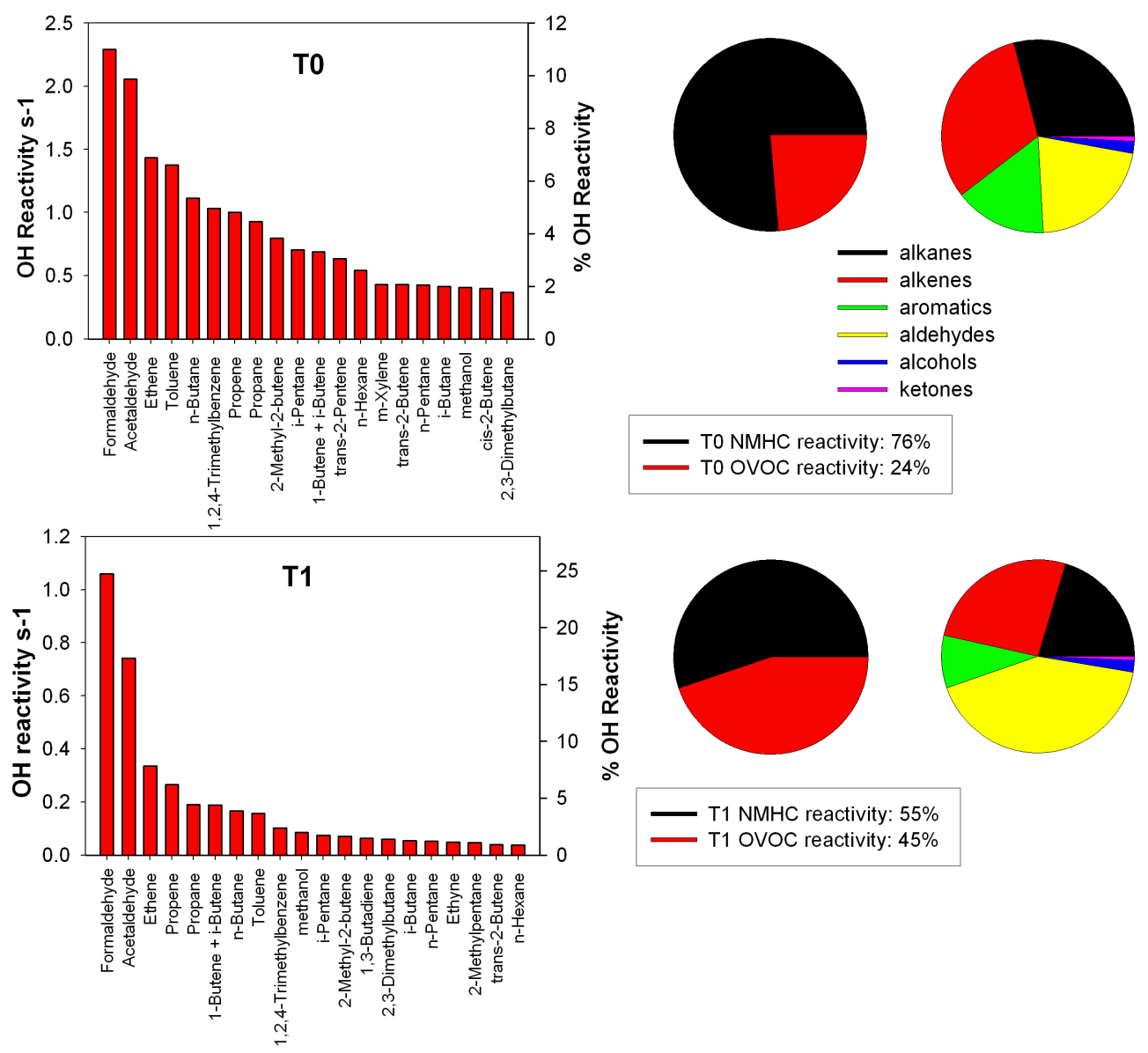

Fig. 3. The top 20 compounds measured at T0 (top panel) and T1 (bottom panel) in terms of OH reactivity between 09:00 and 18:00 local time averaged over the month of March 2006. Shown in the first pie chart to the right of each bar graph is the breakdown for the relative contributions from NMHCs and OVOCs for T0 and T1, respectively. Shown in the second pie chart is the breakdown in terms of each compound class.

for $\mathrm{T} 0$ and $4.4 \mathrm{~s}^{-1}$ for $\mathrm{T} 1$. The pie charts break the reactivity down further, the left pie chart showing the breakdown in terms of NMHC reactivity and OVOC reactivity and the right pie chart in terms of compound class. It is clear that, averaged over the daytime period, NMHCs provide the majority of the measured VOC reactivity for T0 and T1 $(78 \%$ and $57 \%$, respectively), and OVOCs provide the remaining measured VOC reactivity with $22 \%$ and $43 \%$, respectively. The two most important factors in the difference between the VOC distributions shown for $\mathrm{T} 0$ and $\mathrm{T} 1$ are that there are more industrial emissions at $\mathrm{T} 0$ and the air is more processed (aged) at T1.

Despite the fact that the NMHCs provide the majority of the overall VOC reactivity at these sites, the two individual VOCs with the highest $\mathrm{OH}$ reactivity are formaldehyde and acetaldehyde. A number of previous studies have found high ambient levels of formaldehyde in the MCMA (Baez, et al., 1995, 1999; Grutter et al., 2005; Volkamer et al., 2005). Zavala et al. (2006), Garcia et al. (2006) and Lei et al. (2009) concluded that a significant amount of formaldehyde is associated with primary emissions, particularly from mobile exhaust and this has a large impact on the local radical budget. Interestingly, the third most important VOC is ethene which reacts relatively quickly to form formaldehyde (e.g., Wert et al., 2003) and is therefore an important contributor to secondary formaldehyde formation. Indeed, fast 1-s HCHO observations by Fried et al. (2010) over Mexico City also show the importance of secondary sources. On-road vehicle emissions of acetaldehyde were measured by Zavala et al. (2006) who found significant levels of this species in vehicle exhaust although the levels were found to be lower than formaldehyde emissions by a factor of 5-8. Baez et al. $(1995,2000)$ measured carbonyls in the 1990s in Mexico City and found high values of acetaldehyde, of the same order of magnitude reported here. Propene exceeds propane for reactivity despite its much lower abundance (Fig. 2) due to its high reactivity. Nevertheless, propane, although slow reacting, still plays an important role in the $\mathrm{OH}$ reactivity throughout the MCMA 
(Velasco, 2007) because of its high mixing ratio. Propene oxidation readily yields acetaldehyde formation. For the T0 and T1 analyses, 4 of the top 20 species contributing most to the $\mathrm{OH}$ reactivity are OVOCs. The present study presents the most complete coincident VOC coverage to date in the MCMA and as a result there are differences in the attribution of VOC OH reactivity when compared to previous studies (Velasco et al., 2007), however, most of these differences are due to the more complete measurements of OVOCs in this study, which highlights their importance in the overall picture of $\mathrm{VOC} \mathrm{OH}$ reactivity.

It is instructive to examine the $\mathrm{OH}(\mathrm{VOC})$ reactivity diurnal profiles at the ground sites, $\mathrm{T} 0$ and $\mathrm{T} 1$. As indicated earlier, the T0 canister NMHC measurements were not obtained at regular time intervals whereas the $\mathrm{T} 1$ canister data were, with collections taking place every three hours (midnight, 3:00 a.m., 6 a.m., etc.). For T0, there are relatively few measurements from 21:00 to 04:00. Figure 4 shows the diurnal $\mathrm{OH}$ reactivity profiles for $\mathrm{T} 0$ and $\mathrm{T} 1$ averaged over the month of March 2006. The total reactivity shown here only includes the NMHC and OVOC contributions. A clear peak in the total reactivity profile is observed in the morning hours with the maxima reached at both sites during the morning rush hour: $\sim 50 \mathrm{~s}^{-1}$ at $\mathrm{T} 0$ and $\sim 14 \mathrm{~s}^{-1}$ at T1. For both sites, the OVOCs contribute a relatively larger portion in the afternoon to the total reactivity with the OVOCs surpassing the NMHCs in their contribution to the $\mathrm{OH}$ reactivity in the afternoon hours at $\mathrm{T} 1$. These observations may be attributed to high mixing ratios at night when VOC emissions accumulate in a shallow boundary layer followed by further reduction of the boundary layer height in the morning together with some contribution from traffic and industry during the early morning before the boundary layer has expanded. During the day, VOCs are mixed in a deeper boundary layer, processed by photochemistry and the emissions decrease after the morning rush hour (Velasco et al., 2007), all causing a decrease in mixing ratios.

To test the ability of models to capture the VOC OH reactivity, WRF-Chem and MOZART simulated the diurnal profile for the VOC OH reactivity for the MCMA. Figure 5 shows the results of these simulations (WRF-Chem, top panel, MOZART, middle panel) along with the diurnal OVOC reactivity fraction from each model and the experimental data (lower panel). The WRF-Chem results are centered at $\mathrm{T} 1$ and have a horizontal resolution of $6 \times 6 \mathrm{~km}$. The MOZART grid box size is $0.7^{\circ} \times 0.7^{\circ}\left(\sim 75 \times 75 \mathrm{~km}^{2}\right.$ region $)$ covering the greater MCMA, including T0 and T1. The time steps were slightly different for the model output and the experimental data. Both models reproduce some of the features shown in the experimental data. The daytime patterns and absolute values from both models approximate the experimental data although there are some key differences. The WRF-Chem model captures moderately well the total VOC reactivity during the daytime beginning with the hours between 6 a.m. and 9 p.m. However, the model does not
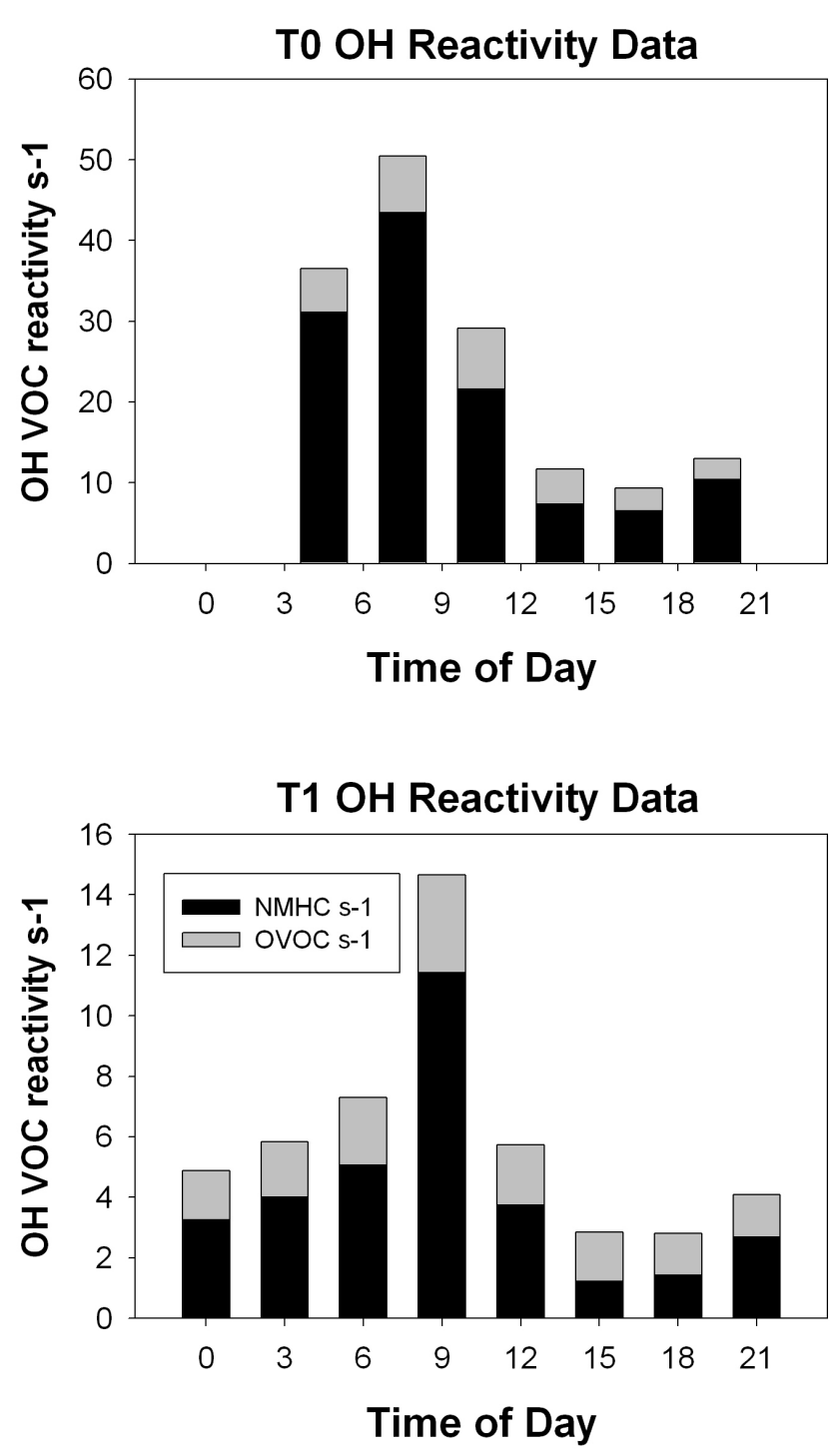

Fig. 4. Diurnal $\mathrm{OH}$ reactivity data for $\mathrm{T} 0$ (upper panel) and $\mathrm{T} 1$ (lower panel) averaged over the month of March 2006. The reactivity data is broken down into NMHCs and OVOCs. The T0 diurnal data is incomplete because of a lack of measurements at the time periods shown.

capture well the relative contribution of OVOCs to the total VOC reactivity (panel c), underestimating their contribution. It is assumed that the large MOZART grid box for Mexico City can be appropriately compared to the T1 data, as T1 is more indicative of the urban/suburban character of the MCMA basin as opposed to strictly the urban city center. The MOZART simulation looks quite similar to the observations for the reactivity during the morning rush hour; however, the model underestimates the VOC reactivity during the remaining daytime hours. In spite of these differences, the relative contributions to the reactivity from OVOCs are better represented in MOZART than in the WRF-Chem model 

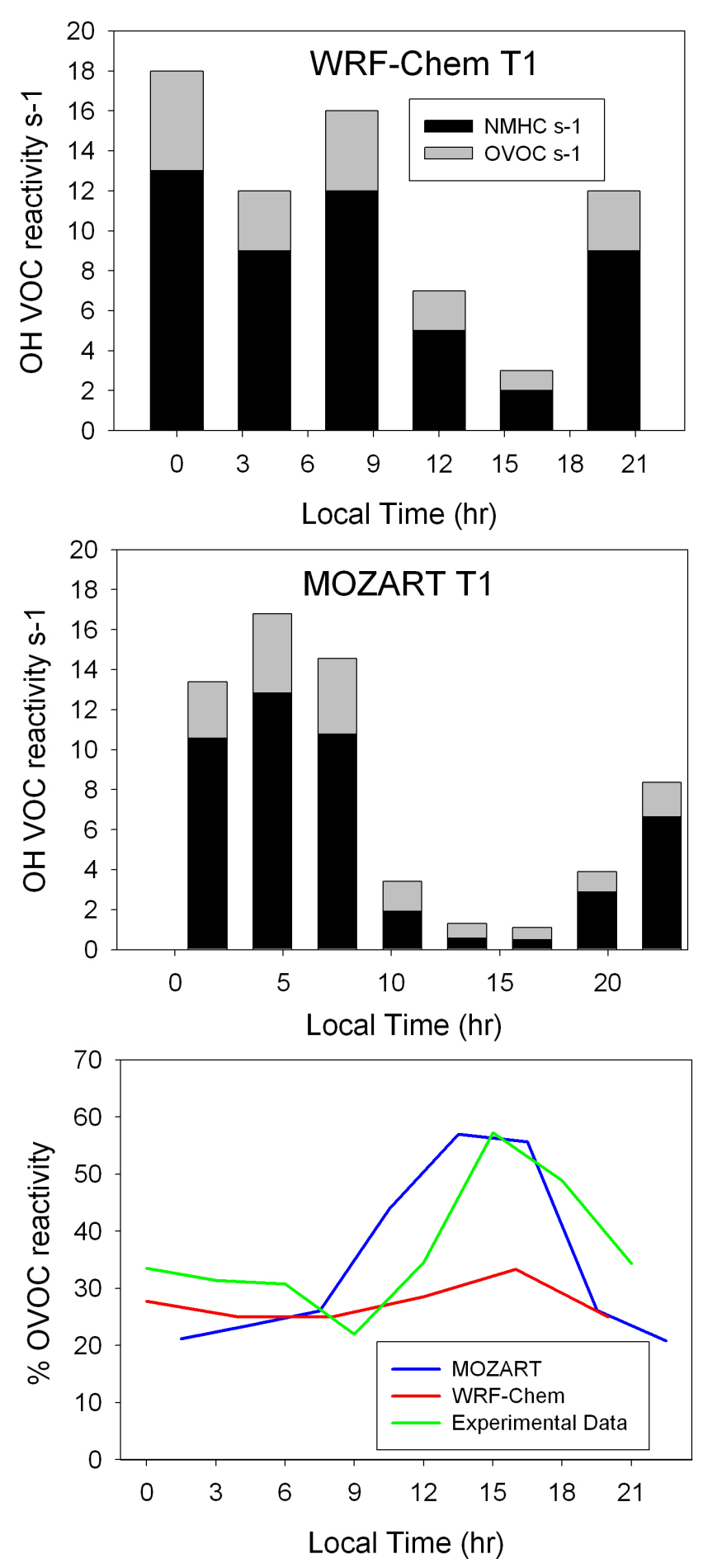

Fig. 5. Diurnal $\mathrm{OH}$ reactivity data for $\mathrm{T} 1$ averaged over the month of March 2006 from the WRF-Chem model (top panel) and MOZART (middle panel). The reactivity data is broken down into NMHCs and OVOCs. The bottom panel shows the relative contribution of OVOCs to the total VOC reactivity for both models and the experimental data.
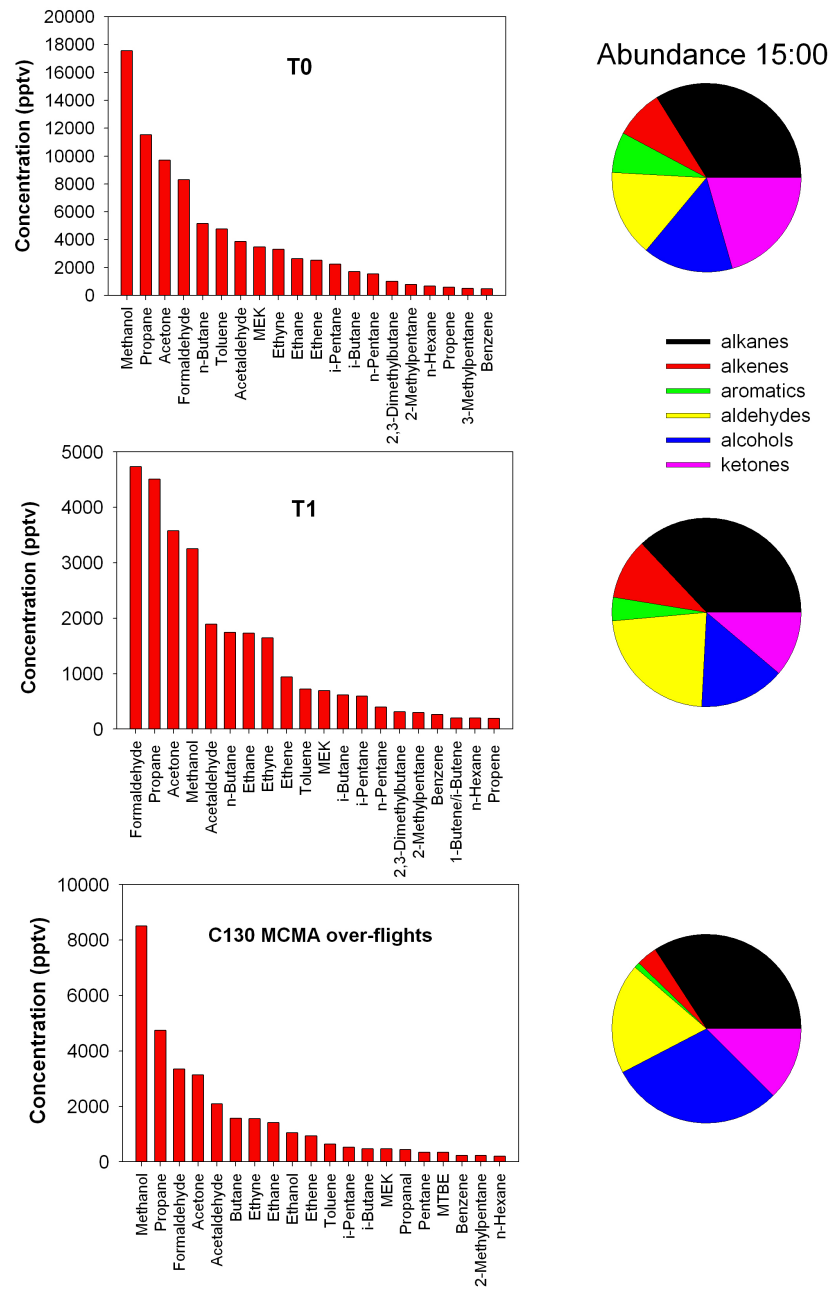

Fig. 6. The top 20 compounds measured from T0 (top panel), T1 (middle panel), and the $\mathrm{C} 130$ platform (lower panel), and in terms of mixing ratios averaged over the month of March 2006, at 3:00 PM, local time. Shown to the right of each bar graph is a breakdown, for T0, T1 and the C130, respectively, for all of the species measured in terms of the sums of the mixing ratios for each compound class.

(lower panel). Large differences between measurements and models occur at night. For the WRF-Chem simulations, there is a problem with either the nighttime emissions or the PBL height; a simulated shallow PBL height would lead to higher surface concentrations during the night which could potentially explain the results. For MOZART, there are clear indications from a number of tracers (e.g., CO, not shown) that the boundary layer height drops too quickly at night.

\subsubsection{C130 over-flight results}

The over-flight data is defined to be the data collected aloft within the grid box shown in the lower panel of Fig. 1. Approximately $75 \%$ of the C130 MCMA over-flight data were collected between 13:00 and 17:00 local time. Figure 6 
(lower panel) shows the averaged mixing ratios for the top 20 VOCs obtained on the $\mathrm{C} 130$ during the over-flights and the pie chart to the right of the bar chart gives the breakdown in terms of compound classes. For comparison, the top and middle panels show data obtained from the T0 and T1 sites, respectively, for a similar sample analysis time period (15:00, local time) with compound class breakdowns shown at the right of each bar graph. There are some interesting similarities and contrasts between the aircraft data aloft and the ground-based measurements.

For the $\mathrm{C} 130$ over-flights, the most abundant species measured was methanol, followed by propane and then other NMHC and OVOC species. Four of the top 5 and 8 of the top 20 measured VOCs were OVOCs. It is interesting to note that methanol was the most prevalent VOC measured aloft (C130) and at the T0 ground site at 15:00, whereas at the $\mathrm{T} 1$ site the most prevalent VOC was formaldehyde. Figure 7 shows the $\mathrm{OH}$ reactivity data presented in a similar fashion to Fig. 3. In all three locations, the two VOCs that have the greatest influence on $\mathrm{OH}$ reactivity are formaldehyde and acetaldehyde. The top four species in the $\mathrm{C} 130$ over-flight analyses are OVOCs. Dilution results in the diminution of the total measured $\mathrm{OH}$ reactivity to $1.9 \mathrm{~s}^{-1}$, but it is clear from the pie chart distributions that the data aloft represent more photochemically processed air than $\mathrm{T} 0$ and $\mathrm{T} 1$. Figure 8 gives insight into differences between the surface and aloft in terms of atmospheric processing. It presents results from a MOZART model simulation over the entire month of March 2006 showing the time series for acetaldehyde and its source contributions at the surface $(764 \mathrm{hPa})$ and at $692 \mathrm{hPa}$ ( $\sim 800 \mathrm{~m}$ above surface). Primary emissions are shown together with secondary production from a number of precursor species. Primary emissions clearly dominate at the surface whereas secondary production dominates aloft demonstrating the much larger degree of photochemical aging aloft compared to the surface in the model.

\subsection{VOC Evolution in MCMA plumes}

On 19 March the C-130 intercepted three times an MCMA outflow plume that had been sampled a day earlier by the G1 over the source region. This was a typical NE transport event at altitudes ranging from $3-5.2 \mathrm{~km}$. Air with a one to two day transport time from the source was sampled. Figure 9 shows the results of a MOZART simulation of the $\mathrm{CO}$ outflow from the city. Superimposed on the plume are flight tracks from the G1 on 18th March and from the C130 on 19th March. The points of interception of the plume are marked for the G1 which intercepted the plume as it was emerging from the city during a transect that occurred between the times of 14:20 and 15:20 local time on the 18th and the C130 which intercepted the plume on the 19th. Also shown in the figure are the $\mathrm{OH}$ reactivity distributions in terms of NMHCs, OVOCs, and $\mathrm{CO}$ for the $\mathrm{T} 0$ and $\mathrm{T} 1$ sites at 9:00 a.m., the G1 during the transect, and the $\mathrm{C} 130$ during the plume interception that oc- curred at the furthest point from the city. Each day in Mexico City, there is a near complete turnover of air in the MCMA basin (de Foy et al., 2006). Thus, it serves the purposes of this discussion to consider the morning hours as the starting point of the plume evolution. Following morning emissions from traffic, industry and cooking, etc., into a shallow boundary layer, the boundary layer rises and the fresh emissions are mixed upwards and eventually transported out of the city. The total VOC reactivity is dominated by NMHCs in the morning with $\mathrm{CO}$ playing a relatively minor role compared to the VOCs. The total measured $\mathrm{OH}$ (VOC) reactivity at 9:00 a.m. at T0 is $50 \mathrm{~s}^{-1}$ and $14 \mathrm{~s}^{-1}$ at T1. A large part of the $\mathrm{OH}$ reactivity is provided by alkenes and aromatics $(50 \%$ of total VOC OH reactivity, with $30 \%$ from alkenes and $20 \%$ from aromatics at $\mathrm{T} 0$, not shown in the figure), species that have relatively short lifetimes under the conditions present in the basin. It is apparent from the data that rapid photochemistry occurs that quickly transforms the $\mathrm{OH}$ (VOC) reactivity from being dominated by NMHCs to being dominated by OVOCs aloft (G1), as noted earlier (see Fig. 8), and further downwind (C130 plumes). At the C130 sampling point, a large part of the VOC reactivity is provided by the OVOCs: aldehydes (65\%); alcohols (15\%); ketones (3\%). The proportional contributions from NMHCs were alkanes (10\%), alkenes (5\%), and aromatics (2\%). As shown in the figure, $\mathrm{CO}$ plays a relatively more important role in $\mathrm{OH}$ reactivity compared to VOCs as the plume ages.

Along with other trace gas measurements aboard the C130, MTBE was used to verify when the C130 intercepted urban plumes. Figure 10 (top panel) shows a time series altitude trace and the lower panel a time series of the TOGA MTBE data for 19 March. The TOGA has the capability of detecting this species down to the 1 pptv level which was very useful in this study. The trace shows the interception points of the plume downwind. Points 1 and $2(\sim 15: 15$ and $\sim 16: 00$, respectively) are clearly interceptions of the same plume layer upon descent and ascent and these are identified as a single point in Fig. 9. Point $3(\sim 17: 00)$ is an interception of the plume at a lower altitude upon return into the MCMA. The higher mixing ratios of MTBE at the beginning and the end of the flights were obtained during transects over the city. In addition to the identification with trace gas measurements, balloon soundings verified that the $\mathrm{C} 130$ intercepted a plume that originated in the MCMA one day earlier (Voss et al., 2007).

Figure 11 shows plots from the 18 and 19 March data that demonstrate some salient points with regard to photochemical processes occurring during the outflow event. The figure shows plots of species versus $\mathrm{CO}$ mixing ratios measured aboard the G1 and C130 during the 18 and 19 March flights, respectively. The top panel shows plots of $\mathrm{O}_{3}$ versus $\mathrm{CO}$ for the $\mathrm{C} 130$ aircraft and the G1 aircraft. Note the difference in slopes between the two measurement platforms. Tie et al. (2009) recently examined the relationship between $\mathrm{O}_{3}$ and $\mathrm{CO}$ as measured by the $\mathrm{C} 130$ aircraft during MIRAGE-Mex 

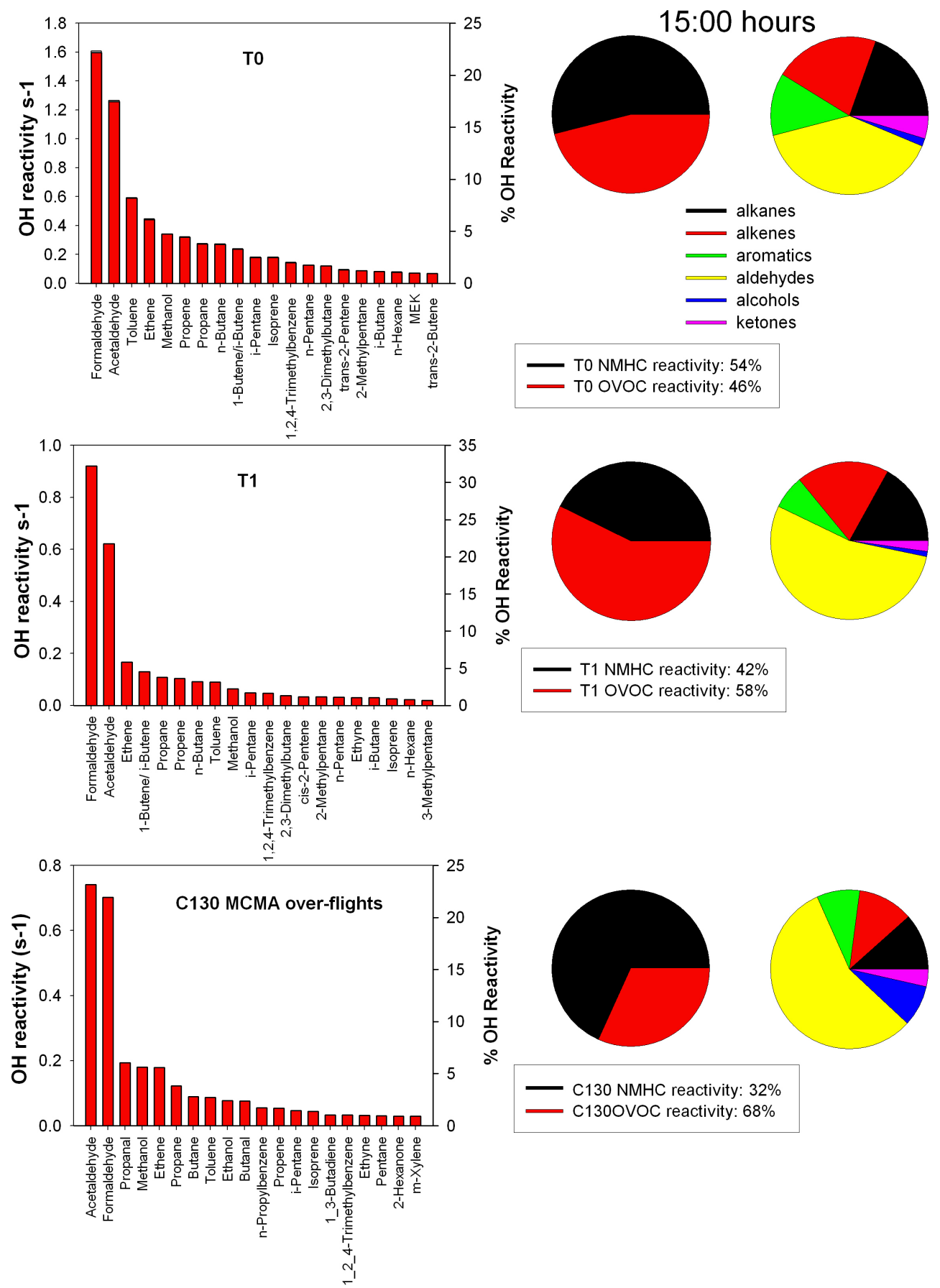

Fig. 7. The top 20 compounds measured from T0 (top panel), T1 (middle panel) and the C130 platform (lower panel), in terms of OH reactivity averaged over the month of March 2006, at 03:00 p.m. Shown in the first pie chart to the right of each bargraph is the breakdown for the relative contributions from NMHCs and OVOCs for T0 and T1, respectively. Shown in the second pie chart is the breakdown in terms of each compound class.

which covered a wide range of regimes from fresh emissions to air that had aged more than two days. The Tie et al. (2009) results from the entire study showed that the $\mathrm{O}_{3}$ $\mathrm{CO}$ correlation is non-linear with a much greater slope observed when $\mathrm{CO}$ concentrations are less than 400 ppbv (aged air) than in less aged air (>400 ppbv). Parrish et al. (1998) studied $\mathrm{O}_{3}-\mathrm{CO}$ correlations at a number of surface sites and found varying slopes of $\Delta\left(\mathrm{O}_{3}\right) / \Delta(\mathrm{CO})$ under different conditions (locations), with larger $\mathrm{O}_{3}-\mathrm{CO}$ slopes often occurring during individual transport events, implying increased 


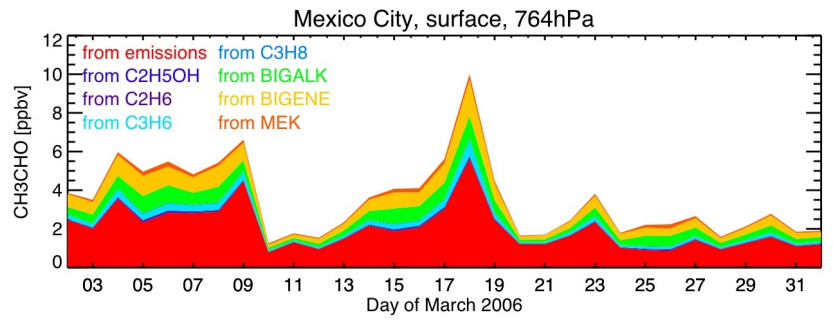

$692 \mathrm{hPa}$

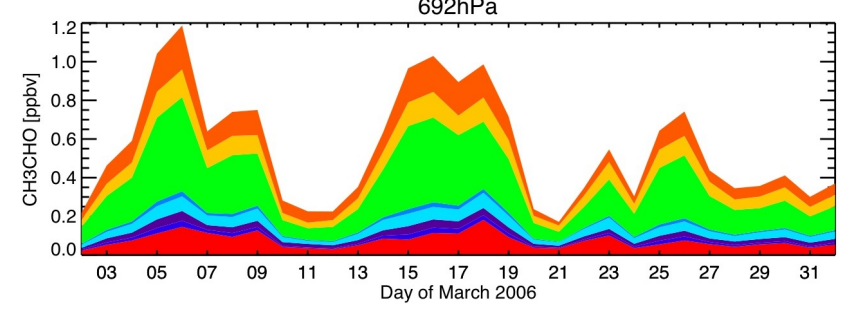

Fig. 8. A MOZART model run over the entire month of March 2006 showing acetaldehyde time series at two different altitudes, at the surface $(764 \mathrm{hPa})$ and at $692 \mathrm{hPa}$. Primary emissions are shown in red whereas secondary production from a number of precursor species are kept track of in the model run and their contributions to the total acetaldehyde mixing ratios are shown in different colors.

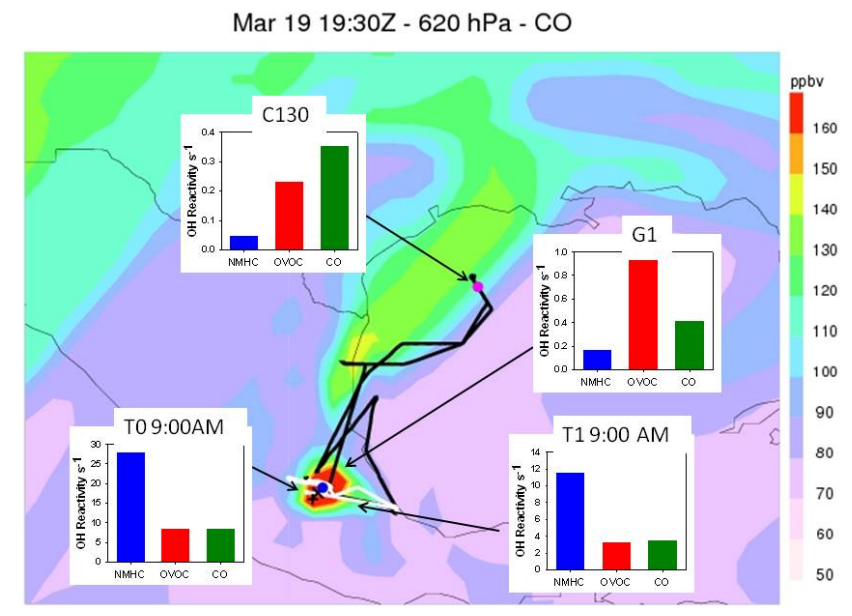

Fig. 9. MOZART depiction of the of the CO outflow from the 19 March plume. Superimposed on the plume are flight tracks from the G1 (white) on 18th March and from the C130 (black) on 19th March. The G1 intercepted the plume as it was emerging from the city during a transect that occurred between the times of 14:20 and 15:20 local time on the 18th and the $\mathrm{C} 130$ which intercepted the plume on the afternoon of the 19th. The $\mathrm{OH}$ reactivity distributions in terms of NMHCs, OVOCs, and CO at 09:00 a.m. are shown for the T0 and T1 sites, the $\mathrm{G} 1$ during the transect, and the $\mathrm{C} 130$ during the plume interception that occurred at the furthest point from the city.

$\mathrm{O}_{3}$ production efficiency during these events. These results are consistent with the study by Wood et al. (2009) who found that the ratio $\Delta\left(\mathrm{O}_{3}\right) / \Delta(\mathrm{CO})$ increases with the age of MCMA plumes. The lower panel shows plots of benzene

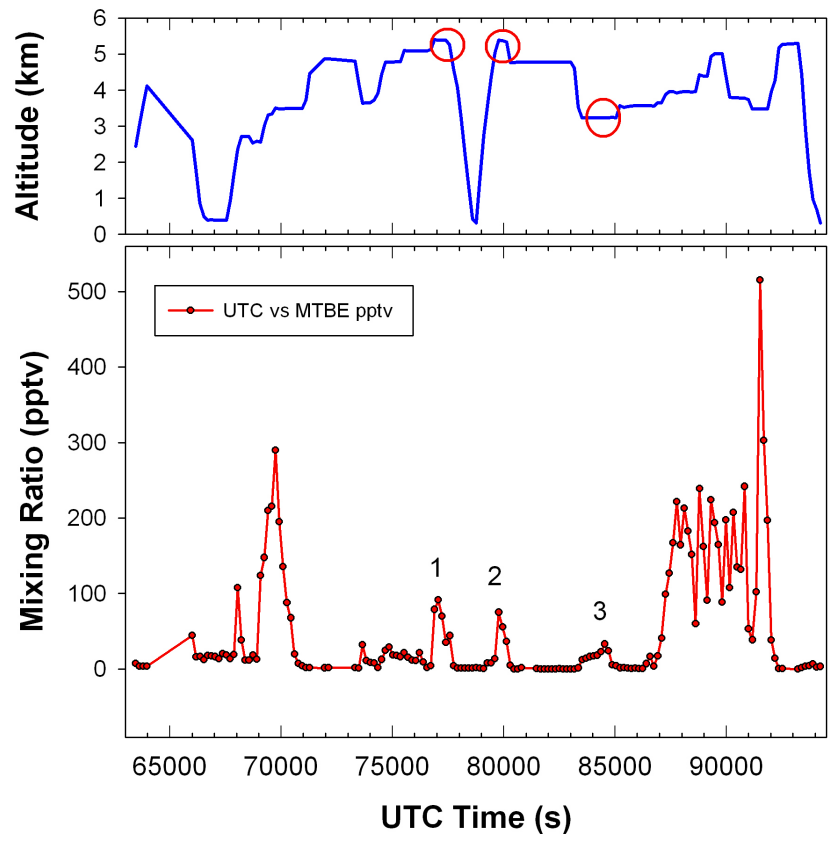

Fig. 10. Time series traces for the altitude (top panel) and the TOGA measurements of MTBE (bottom panel) during the 19 March flight in which the outflow plume was followed. Red circles mark the regions on the altitude profile where the plume was intercepted. These interception regions are seen on the MTBE profile and are labeled as 1,2 , and 3 .

versus $\mathrm{CO}$. Benzene is not expected to be produced photochemically and has a long lifetime ( $>5$ days) relative to the age of air mass $(<2$ days $)$ at the time of the measurement. Thus, a good correlation is expected from either measurement platform with a slope equal to the emission ratio. This is indeed what is observed with the slopes from the G1 or the $\mathrm{C} 130$ being similar, with differences within experimental error.

Shorter - lived species do not generally correlate with $\mathrm{CO}$ except for very short photochemical ages due to the fact that the loss rate of these species is rapid compared to $\mathrm{CO}$, i.e., correlations can exist only for fresh emissions. Thus, a different approach is necessary to examine the possible photochemical production of species that react quickly. In Fig. 12, we show plots of acetaldehyde, methyl tertiary butyl ether (MTBE), and toluene from the entire MIRAGE-Mex C130 experiment versus the calculated photochemical lifetime. Before discussing the details of Fig. 12, a brief discussion is given below of the photochemical lifetime calculation.

Along with $\mathrm{CO}$, toluene and benzene are emitted directly by vehicles. Both react with the hydroxyl radical $(\mathrm{OH})$, but at different rates; the OH-benzene rate constant is $1.22 \times 10^{-12} \mathrm{~cm}^{3}$ molecules ${ }^{-1} \mathrm{~s}^{-1}$ while the $\mathrm{OH}$-toluene rate constant is $5.63 \times 10^{-12} \mathrm{~cm}^{3} \mathrm{molec}^{-1} \mathrm{~s}^{-1}$ (Atkinson and Arey, 2003). Thus, more photochemically aged plumes should have smaller toluene/benzene ratios. Using an 

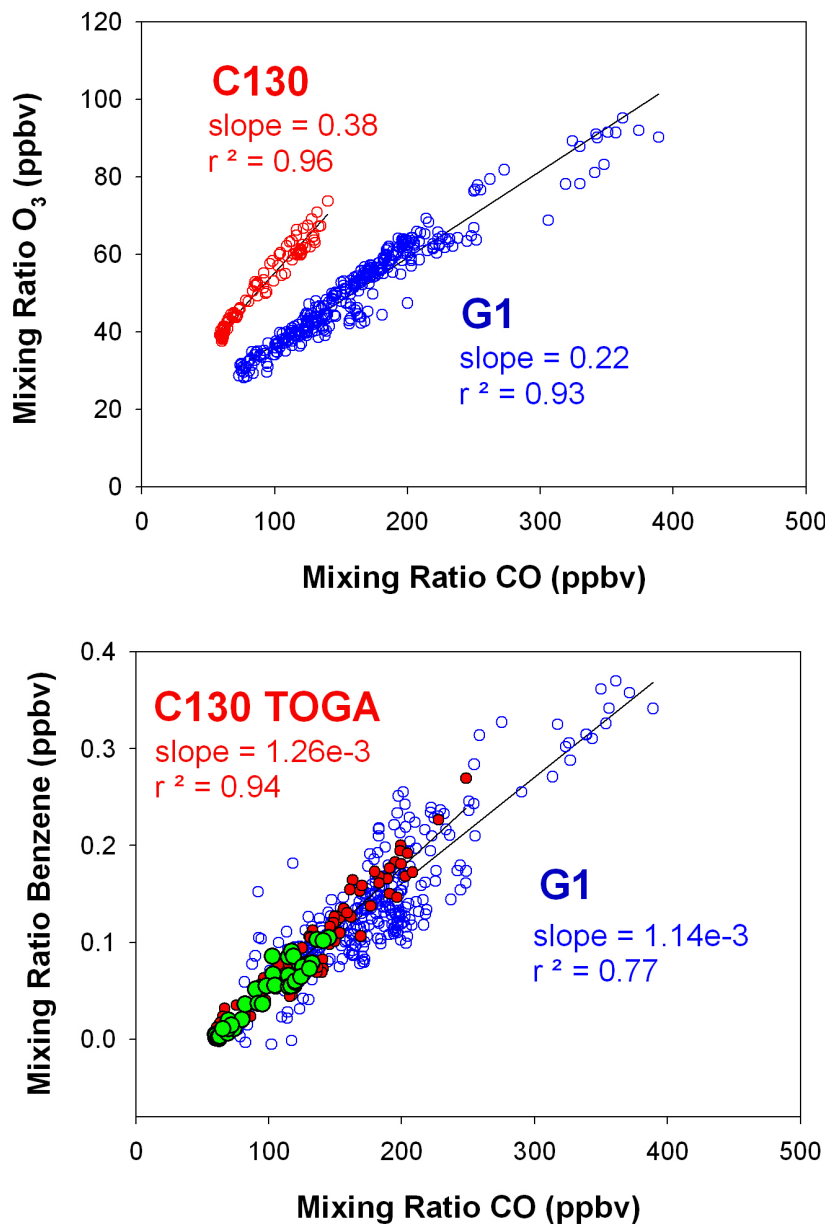

Fig. 11. Plots of CO mixing ratios versus ozone and benzene measured aboard the G1 and C130 during the 18 March (blue) and 19 March (red and green) flights, respectively. The C130 data shown in the top panel is from the NASA one minute data merge (http://www-air.larc.nasa.gov) and encompasses data collected during the outlow event from UTC 2100 to UTC 2400. It excludes data from the boundary layer run during this time period since these data are not part of the outflow event. The C130 data shown in the bottom panel is taken from the NASA TOGA data merge (http://www-air.larc.nasa.gov). The green data points encompass the data for the entire flight and the red data points encompass data from the outflow similar to the $\mathrm{C} 130$ data in the top panel. The slopes and intercepts are shown for each respective set of G1 and C130 data. The benzene/CO slope does not change whether observed in or out of the outflow.

estimate of the emission ratio of toluene to benzene of 5 (Zavala, 2006; Karl et al., 2009, and this study) and an average measured $\mathrm{OH}$ concentration $\left(3.5 \times 10^{6} \mathrm{molec}^{-3}\right)$, the photochemical age of the air mass can be estimated (Roberts et al., 1984; McKeen et al., 1996; Gelencsér et al., 1997) by

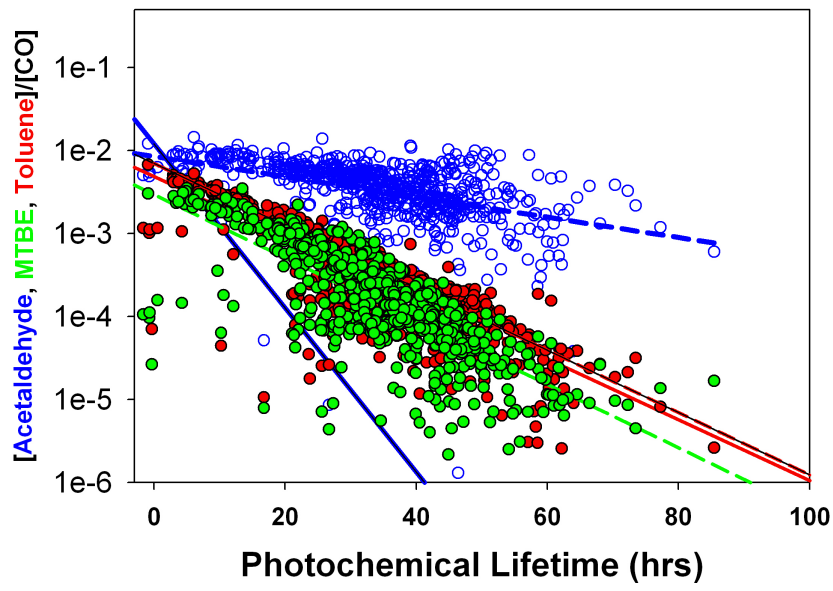

Fig. 12. Plots of acetaldehyde, methyl tertiary butyl ether (MTBE), and toluene all ratioed to $\mathrm{CO}$ versus the photochemical lifetime for the entire MIRAGE-Mex C130 experiment. Regression lines (dashed) are drawn through each compound data set. Solid lines are drawn showing the calculated expected pseudo first order decay with time for each respective compound using the highest mixing ratios as the starting point for the decay curve. An average experimentally-derived value of $[\mathrm{OH}]=3.2 \times 10^{6}$ was used in the calculations. The toluene/benzene emission ratio used in the calculations of photochemical lifetime is 5:1 (Karl et al., 2009; Zavala et al., 2006).

$\Delta t=\frac{1}{[\mathrm{OH}]\left[k_{\text {toluene }}-k_{\text {benzene }}\right]}$
$\cdot\left[\ln \left(\frac{[\text { toluene }]}{[\text { benzene }]}\right)_{t=0}-\ln \left(\frac{[\text { toluene }]}{[\text { benzene }]}\right)\right]$

The emission ratio of toluene to benzene results from a combination of sources including mobile, fire (Yokelson et al., 2007; Crounse et al., 2009) and industrial (Karl et al., 2009).

In Fig. 12, regression lines (dashed) are drawn through each compound data set. In addition, lines (solid) are drawn showing the calculated expected pseudo first order decay with time using the highest mixing ratios as the starting point for the decay curve. Note that for toluene, a species for which there is no expected photochemical production, the calculated decay closely matches the observed decay. For MTBE, also a species that is not expected to be produced photochemically, the calculated decay is somewhat, although not dramatically, slower than the observed decay. Some differences in the calculated versus observed decay are expected and may be attributable to the mixing of air masses of different ages since Reaction (R5) is valid only for an isolated air parcel. However, for acetaldehyde, the expected decay is much faster than the observed decay which is compelling evidence for photochemical production with time for this species. Like formaldehyde, numerous VOC precursors lead to its production. These include ethane, $\mathrm{C}_{4}, \mathrm{C}_{5}, \mathrm{C}_{6}$ alkanes and alkenes, 


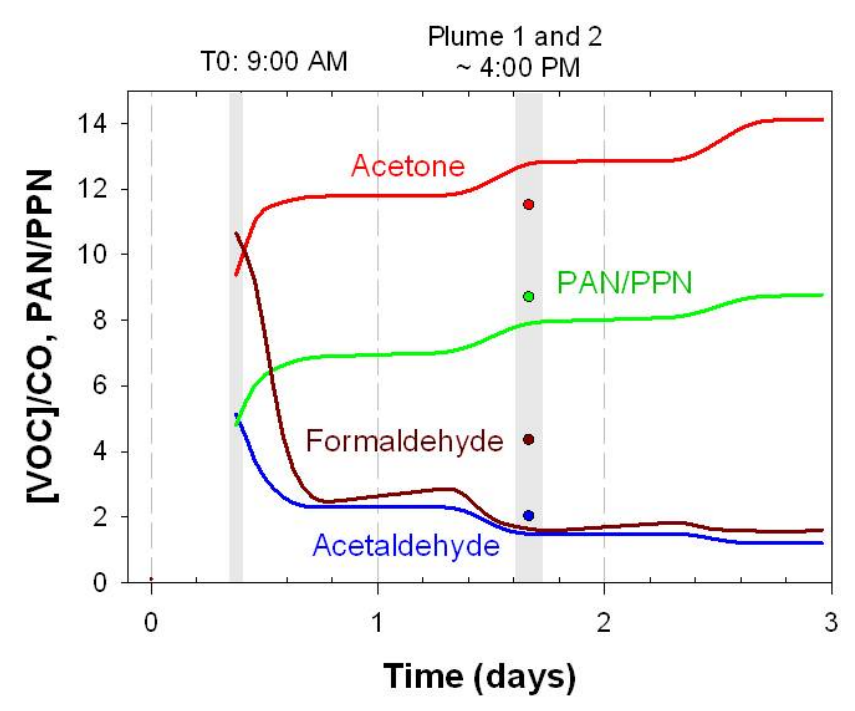

Fig. 13. Results of a MM model run initialized with T0 data as a function of the processing time as calculated by the Master Mechanism. In order to eliminate the effects of dilution, the speciated data are normalized to carbon monoxide concentrations.

methyl ethyl ketone, ethanol, etc., which can lead to a continuous production of acetaldehyde as the plume progresses in space and time.

To take a closer look at processes leading to acetaldehyde and other OVOC production, we utilized the NCAR Master Mechanism. The box model offers an opportunity to examine chemical transformations of an isolated urban plume at a level of detail that is impractical to implement in current 3D models. More detail on the box model study will be given in a future publication and we will restrict our discussion here to looking at trends and results for a subset of VOC species that are discussed elsewhere in this paper. The model starting point VOC mixing ratios are the T0 conditions at 9:00 a.m., i.e., the same conditions that result in the $\mathrm{OH}$ reactivity plot for $\mathrm{T} 0$ in Fig. 9. In addition to the VOC input, ozone was set to $35 \mathrm{ppbv}$, NO to $50 \mathrm{ppbv}$, and methane and $\mathrm{CO}$ were set to their averaged measured values of 2200 and 3600 ppbv, respectively. Figure 13 shows a plot of ratios of species concentrations to [CO] as a function of the time of day as calculated by the Master Mechanism. The species concentrations are normalized to carbon monoxide concentrations to eliminate the effects of dilution. To test the model we also included the ratio of peroxyacetyl nitrate (PAN) to peroxypropionyl nitrate (PPN) in the model run. In this run we started at zero for PAN and PPN and generated mixing ratios with the photochemistry in the model. It takes time to spin up to the correct values. In the model, the production of acetone outpaces its decay (relative to $\mathrm{CO}$ ) over the period of the study and the results are consistent with the data shown in Fig. 11. Because of their high reactivity, formaldehyde and acetaldehyde decay more quickly than they are produced despite significant production over the course of several days.
In the absence of production, the values for formaldehyde and acetaldehyde would quickly fall to near zero during daytime photochemical processing. The photochemical processing results shown here are consistent with modeling results obtained by Sommariva et al. (2008). Data taken from the $\mathrm{C} 130$ as it intercepted the plume at $t=1.6$ days, i.e., the afternoon of the following day, are shown as colored dots on the figure. The indicator of plumes 1 and 2 in this figure refer to the plumes shown in Fig. 10 in the Mexico City outflow on 19 March. The processing time presented here is consistent with results obtained from balloon profiling of the outflow by Voss et al. (2010). In the real world the plume is not an isolated air parcel and it may be perturbed by additional sources such as biomass burning and mixing with other urban sources (see Voss et al. (2010) for more discussion). Biomass burning influences, for example, would tend to increase the measured to modeled values of all parameters shown in the plot. Despite these complications, the general trends are reproduced for the VOC species and the model closely predicts the PAN/PPN ratio. Measured formaldehyde values are clearly higher than the modeled values. A possible reason for this is that there are additional formaldehyde precursors that were not accounted for in the model. This is will be the subject of a future publication by Fried et al. (2010).

As a test of the sensitivity of the model to specific compounds, we ran the model, again initialized at T0 with and without methanol and ethanol which are precursors to formaldehyde and acetaldehyde, respectively, as shown by the following reactions (e.g., Atkinson, 1989):

$$
\begin{aligned}
& \mathrm{CH}_{3} \mathrm{OH}+\mathrm{OH} \rightarrow \mathrm{CH}_{2} \mathrm{OH}+\mathrm{H}_{2} \mathrm{O} \\
& \mathrm{CH}_{2} \mathrm{OH}+\mathrm{O}_{2} \rightarrow \mathrm{HCHO}+\mathrm{HO}_{2} \\
& \mathrm{CH}_{3} \mathrm{CH}_{2} \mathrm{OH}+\mathrm{OH} \rightarrow \mathrm{CH}_{2} \mathrm{CH}_{2} \mathrm{OH}+\mathrm{H}_{2} \mathrm{O} \\
& \mathrm{CH}_{2} \mathrm{CH}_{2} \mathrm{OH}+\mathrm{O}_{2} \rightarrow \mathrm{CH}_{3} \mathrm{CHO}+\mathrm{HO}_{2}
\end{aligned}
$$

Ethanol was estimated from the TOGA data by using TOGA-derived emission ratios. The results, shown in Fig. 14, indicate that methanol is an important contributor to formaldehyde formation, e.g., two days downwind, the sensitivity study predicts that methanol oxidation contributes $\sim 20 \%$ of the formaldehyde. The study also indicates that ethanol is an important contributor to acetaldehyde formation both near field and far field with contributions up to $~ 30 \%$ of the acetaldehyde mixing ratio. Methanol has been measured for a number of years (e.g., Singh et al., 1995) and its distributions are beginning to be understood (e.g., Heikes et al., 2002; Galbally et al., 2002; Millet et al., 2008), however, the sources of methanol in the MCMA are uncertain, given the magnitude of mixing ratios observed in this study (see Figs. 2, 5), even though there is some indication that industrial sources and solvent usage may be important (Velasco et al., 2005). Because of its relatively low reactivity, methanol's influence on formaldehyde formation is less pronounced in 

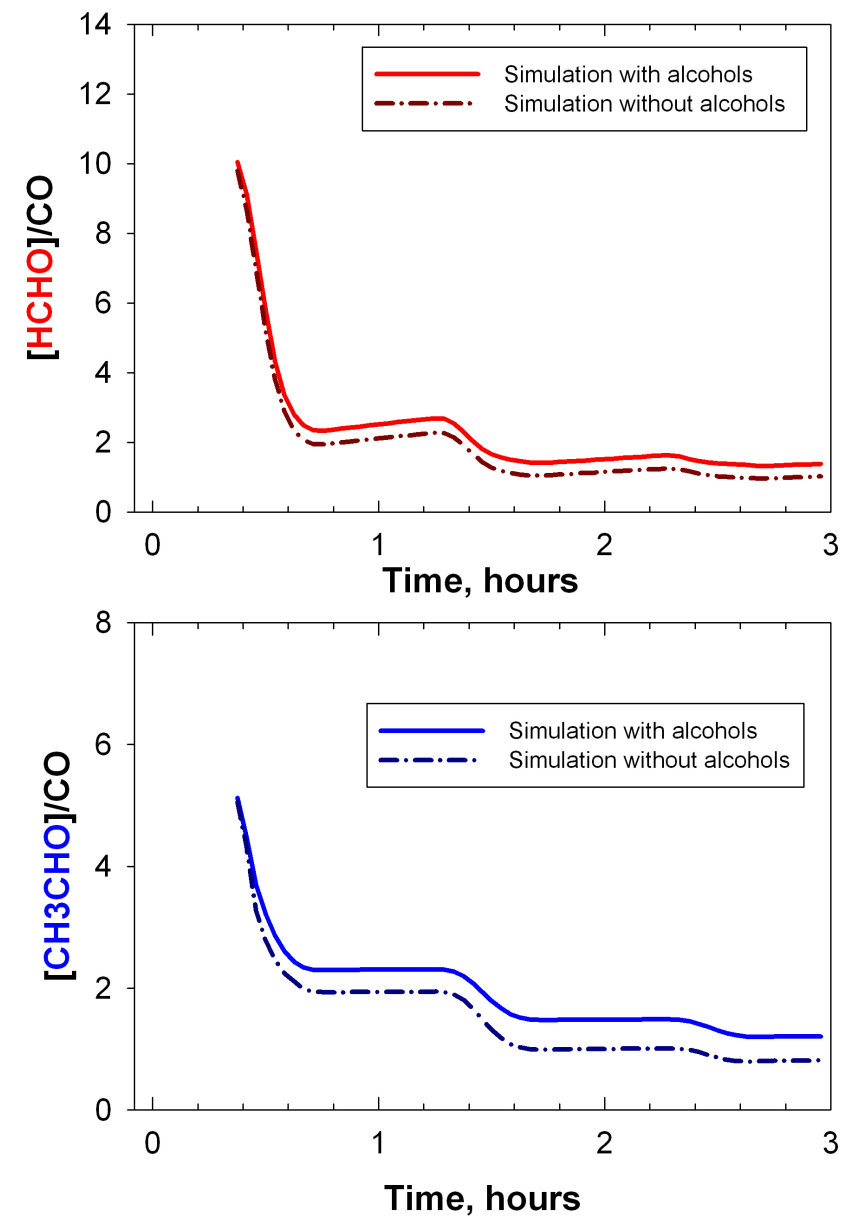

Fig. 14. Results of a MM model run to test of the sensitivity of the model to specific compounds. The model was initialized with T0 data and results are shown with respect to time for formaldehyde and acetaldehyde concentrations with and without methanol and ethanol in the starting data to test to the contribution from alcohols to the respective aldehyde concentrations.

the near field but still significant and because of its low reactivity it can continue to produce formaldehyde far downwind of the source given sufficient $\mathrm{NO}_{\mathrm{x}}$ and sunlight. Ethanol on the other hand has been scarcely measured and is most often not included in model simulations. This is of topical interest as ethanol is being added to motor fuels throughout large regions of the world.

To further examine the characteristics of the 19 March plume, we utilized both MOZART and the WRF-Chem model. Figure 15 shows the plume from a MOZART simulation for ozone produced from emissions in Mexico City and its surrounding areas (top left panel) and $\mathrm{VOC} \mathrm{OH} \mathrm{reac-}$ tivity (top right panel). It is interesting to note the extent of the plume into the US at $620 \mathrm{hPa}(\sim 4 \mathrm{~km})$. Also shown in the lower panels of the figure are curtain plots of the $\mathrm{VOC} \mathrm{OH}$ reactivity taken at points along latitude transects (red) that coincide with latitudes for which sampling of the plume oc- curred from the $\mathrm{G} 1$ and $\mathrm{C} 130$ platforms. The bottom red line represents the approximate latitude for Mexico City and this is also the approximate latitude where the G1 sampling took place on 18 March. The top two red lines represent latitudes where the C130 intercepted the plume during the 19 March flight. At the various latitudes, the $\mathrm{OH}$ reactivity is broken down into the reactivity originating from the NMHCs and OVOC compound classes. The reactivity is captured quite well in the model as the plume evolves, diffuses and is transported, including the essential feature of the increasing relative importance of OVOCs versus NMHCs as the plume evolves (see Fig. 9 for a comparison with measurements). The model shows a maximum in the distribution at a height of $4 \mathrm{~km}$ at $27.2 \mathrm{~N}$. Recall from Fig. 10 that the measurements on board the $\mathrm{C} 130$ showed an outflow maximum at approximately $5 \mathrm{~km}$ altitude, indicating a minor model error in the transport height of the pollution.

Figure 16 shows a vertical cross-section from a WRFChem regional model run extending from the MCMA to $1000 \mathrm{~km}$ downwind that included chemistry as discussed by Tie et al., 2009. The species tracked in the figure are grouped and include $\mathrm{CO}$, relatively slow reacting VOCs (alkanes), reactive to very reactive VOCs (alkenes and aromatics), and OVOCs. The rate of the alkenes + aromatics reactions with $\mathrm{OH}$ is high (about 20-100 times higher than the $\mathrm{CO}+\mathrm{OH}$ reaction rate). As discussed earlier, this fast reaction leads to high $\mathrm{OH}$ reactivity in the city area, and this is normally a major contributor to the high rate of ozone formation in Mexico City (Madronich, 2006; Tie et al., 2007, 2009). As a result, a large portion of the reactive alkenes + aromatics is chemically destroyed near the city, and a smaller amount of alkenes + aromatics is transported downwind of the city, leading to a small contribution to the $\mathrm{OH}$ reactivity in the aged plume, in accord with observations. OVOCs have primary and secondary sources but as we have seen, these species are primarily secondary products downwind of the city, produced by chemical reactions of numerous VOC precursors including the reactions of $\mathrm{OH}$ with alkanes, alkenes, aromatics, and other OVOCs. Thus, consistent with experimental results, the model results indicate that OVOCs are continuously produced along the plume and this significantly contributes to the $\mathrm{OH}$ reactivity near the city but, more importantly in a relative sense, in the aged plume. The rate of alkane reactions with $\mathrm{OH}$ is relatively low compared to alkenes and aromatics. As a result, alkanes contribute to the $\mathrm{OH}$ reactivity in both young and aged plumes, but are usually not the dominant species in either. Note that the values derived from the model (Fig. 16) versus the measurements (Fig. 9) are in reasonable agreement. Similar to the MOZART results, the WRF-Chem model predicts a lower outflow altitude than the measurements would suggest (Fig. 10). 


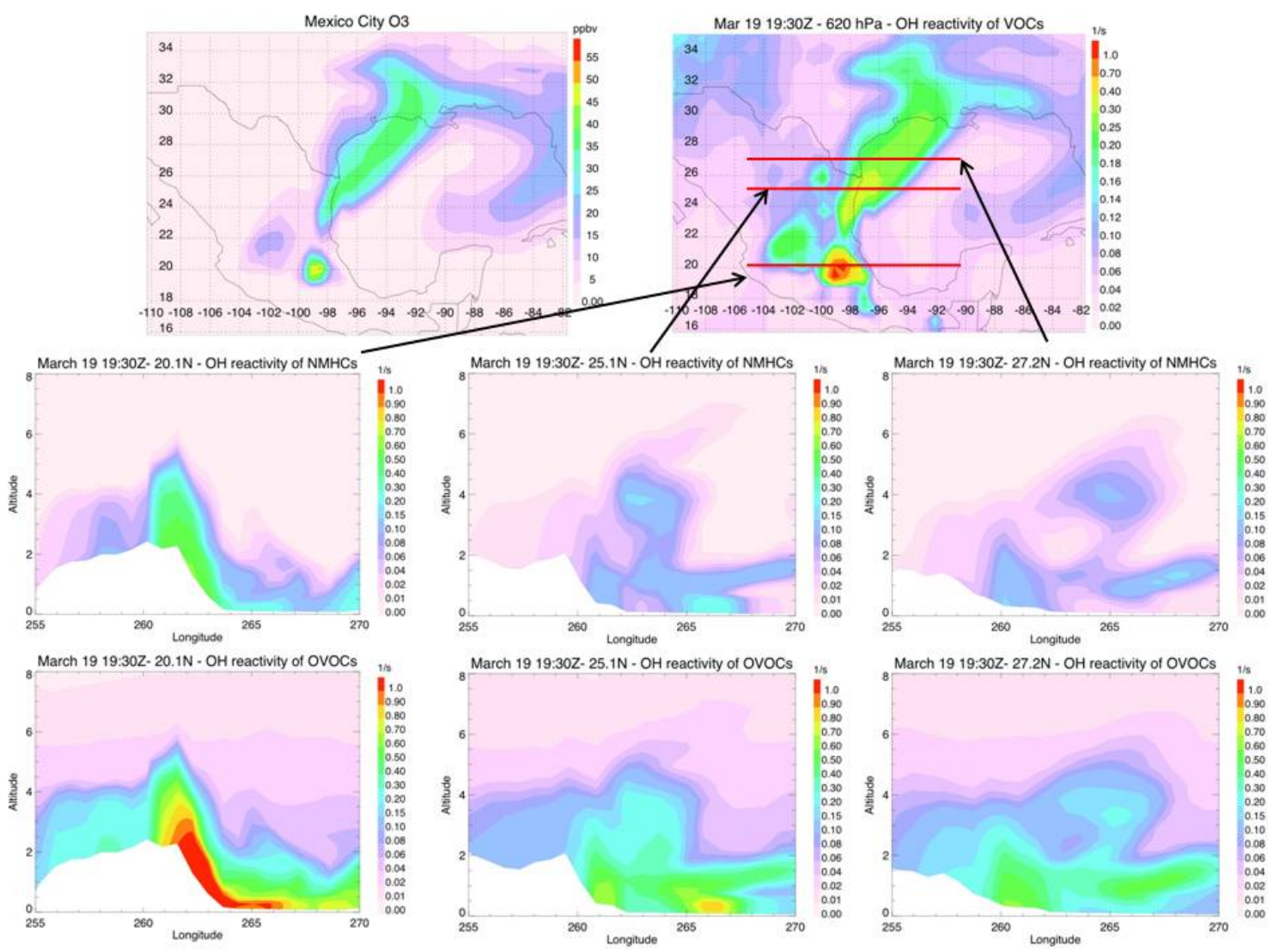

Fig. 15. MOZART simulation for ozone produced from emissions in Mexico City and its surrounding areas (top left panel) and VOC OH reactivity (top right panel). Curtain plots of the VOC OH reactivity taken at points along latitude transects (red) that coincide with latitudes in which sampling of the plume occurred from the G1 and C130 platforms. The bottom red line represents the approximate latitude for Mexico City and this is also the approximate latitude where G1 sampling took place on 18 March. The top two red lines represent latitudes where the $\mathrm{C} 130$ intercepted the plume during the 19 March flight. At the various latitudes, the $\mathrm{OH}$ reactivity is broken down into the reactivity originating from the NMHCs and OVOC compound classes.

\section{Summary and conclusions}

The VOC distribution in the Mexico City Metropolitan Area and its evolution as it is uplifted and transported out of the MCMA basin was studied during the MIRAGE-Mex field campaign. The ground-based and in-situ aircraft measurements of VOCs were analyzed, and interpreted with a global model, MOZART, a regional chemical/transport model (WRF-Chem), and a box model (NCAR Master Mechanism). The results show that in the morning hours (6 a.m.-9 a.m.) near the city center, the VOC mixing ratio distribution is dominated by NMHCs (vs. OVOCs). Even though there is a substantial contribution from OVOCs, most of these are likely primary emissions during this time period. Alkanes account for a large part of the VOC burden. NMHCs dominate the overall $\mathrm{OH}$ reactivity, especially in the morning hours. However, in the afternoon, as the boundary layer lifts and air is mixed and aged within the basin, the distribution changes as secondary products are formed from the primary emissions. The WRF-Chem model and
MOZART were able to approximate the observed MCMA daytime patterns and absolute values of the $\mathrm{VOC} \mathrm{OH}$ reactivity. The MOZART model is also in agreement with observations showing that NMHCs dominate the reactivity distribution except in the afternoon hours. Discrepancies with the models were observed during the evening hours, most likely due to an under-prediction of the PBL height during nighttime and early morning; in addition, WRF-Chem underpredicts the contribution of OVOCs to the VOC reactivity during the daytime.

Instruments on-board the G1 and C130 aircraft measured the VOC distributions aloft over the MCMA, mostly during the afternoon hours. The observations show that as air is uplifted, rapid chemical processing occurs, leading to a distribution that is dominated by OVOCs. The MOZART model simulation for the month of March shows that primary emissions for one of the most important OVOCs, acetaldehyde, dominate at the surface whereas secondary production dominates aloft, in accord with experimental observations of the increasing importance of OVOCs aloft and the 


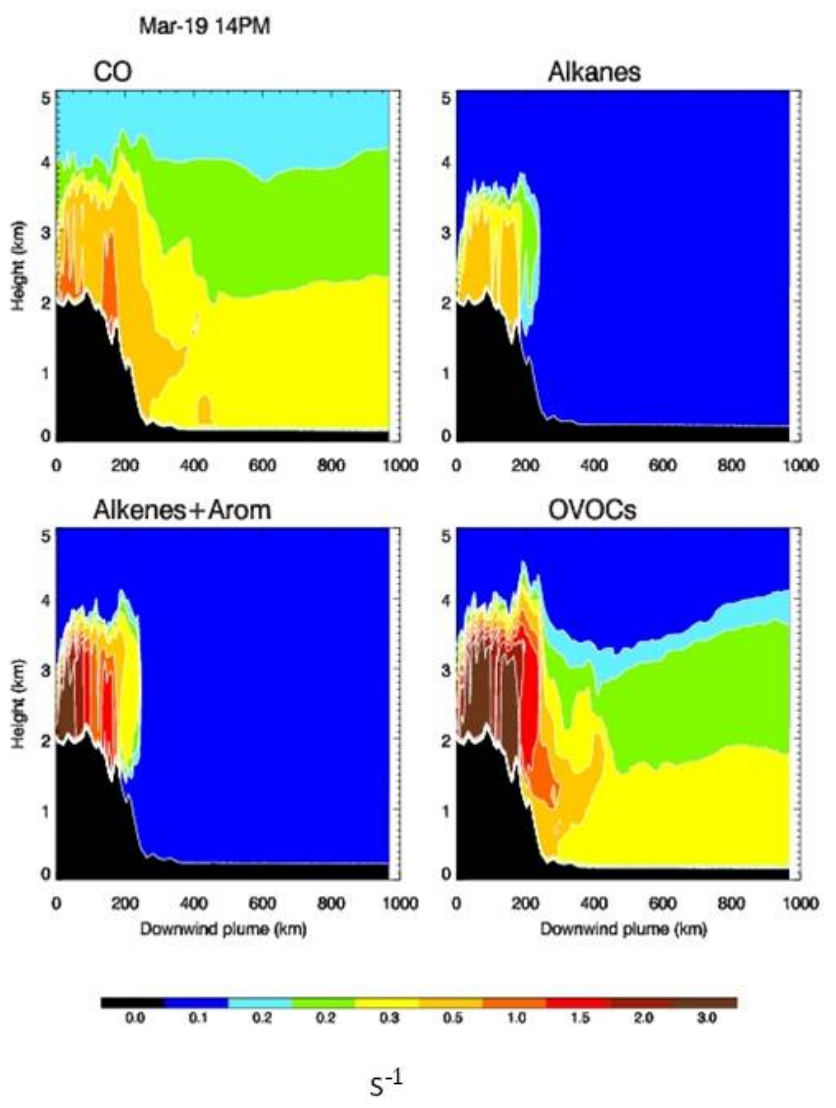

Fig. 16. WRF-Chem regional model run extending from the MCMA to $1000 \mathrm{~km}$ downwind. The panels show the $\mathrm{OH}$ reactivity contributions from $\mathrm{CO}$ and various VOCs as calculated by the model from 0-1000 km downwind.

decreasing importance of NMHCs as they are reacted away to form products.

In addition, a northeast transport event was studied in which air originating in the MCMA was intercepted aloft with the DOE G1 on 18 March and downwind with the National Center for Atmospheric Research NCAR C130 one day later on 19 March. It was shown that ozone was photochemically produced in the plume. The NCAR Master Mechanism was used to help interpret the results using the VOC distributions from the city center for the model initialization. These results showed that the mixing ratios and general trend of important species downwind could be reproduced using the detailed chemistry of the MM. A sensitivity test was also performed by including the alcohols, methanol and ethanol, in one of the simulations and excluding them in another. These results showed that methanol and ethanol are important precursors to formaldehyde and acetaldehyde downwind and that it is clearly important to measure these species in major field campaigns with their importance increasing because of increased usage in fuel formulations. The WRF-Chem model and MOZART were used to examine the spatial and temporal extent of the 19 March plume and also to interpret the $\mathrm{OH}$ reactivity in the downwind plume. The results showed generally good agreement for the total VOC OH reactivity downwind and also gave insight into the distributions of VOC chemical classes downwind. The models clearly support the experimental evidence for NMHCs fueling the formation of OVOCs downwind, which then become the primary fuel for ozone production downwind of the city.

Acknowledgements. The authors would like to thank University of New Hampshire students Karl Haase, Rich Luciano, and Theresa Balanger for their incredible work with chromatograms. Thanks also to Geoff Tyndall and Rebecca Hornbrook for helpful discussions. We gratefully acknowledge the NASA Tropospheric Chemistry Program for funding this research (award number NNG06GB29G). The National Center for Atmospheric Research is sponsored by the National Science Foundation.

Edited by: L. Molina

\section{References}

Altuzar, V., Tomás, S. A., Zelaya-Angel, O., Sánchez-Sinencio, F., and Arriaga, J. L.: Atmospheric ethene concentrations in Mexico City: Indications of strong diurnal and seasonal dependences, Atmos. Env., 39, 5219-5225, 2005.

Apel, E. C., Calvert, J. G., and Fehsenfeld, F. C.: The Non-Methane Hydrocarbon Intercomparison Experiment (NOMHICE): Tasks 1 and 2, J. Geophys. Res., 99(D8), 16651-16664, 1994.

Apel, E. C., Calvert, J. G., Gilpin, T., Parrish, D. D., and Fehsenfeld, F. C.: The Non-Methane Hydrocarbon Intercomparison Experiment (NOMHICE): Task 3, J. Geophys. Res., 104, 26069-26086, 1999.

Apel, E. C., Hills, A. J., Lueb, R., Zindel, S., Eisele, S., and Riemer, D. D.: A Fast-GC/MS system to measure $\mathrm{C}_{2}$ to $\mathrm{C}_{4}$ carbonyls, and methanol aboard aircraft, J. Geophys. Res., 108, 8794, doi:10.1029/2002JD003199, 2003.

Atkinson, R. and Arey, J.: Chem. Rev., 103, 1-246, 2003.

Atkinson, R.: Gas phase tropospheric chemistry of organic compounds: a review, Atmos. Environ., 24A, 1-41, 1990.

Atkinson, R., Kinetics and mechanisms of the gas phase reactions of the hydroxyl radical with organic compounds, J. Phys. Chem. Ref. Data, Monograph 1, 1, 4605-4638, 1989.

Baez, A. P., Belmont, R., and Padilla, H.: Measurements of formaldehyde and acetaldehyde in the atmosphere of Mexico City, Environ. Poll., 89, 163-167, 1995.

Baez, A. P., Padilla, H., Torres, M. C., and Belmont, R.: Ambient levels of carbonyls in Mexico City, Atmosfera, 13, 121-131, 2000.

Baker, A. K., Beyersdorf, A. J., Doezema, L. A., Katzenstein, A., Meinardi, S., Simpson, I. J., Blake, D. R., and Rowland, F. S.: Measurements of nonmethane hydrocarbons in 28 United States cities, Atmos. Environ., 42, 170-182, 2008.

Baker, A., et al.: VOC Measurements in the MCMA basin during MIRAGE -MEX, Atmos. Chem, Phys., to be submitted, 2010.

Blake, D. and Rowland, F. S.: Urban leakage of liquefied Petroleum Gas and Its Impact on Mexico City Air Quality, Science, 269, 953-956, 1995. 
Chang, J. S., Binkowski, F. S., Seaman, N. L., McHenry, J. N., Samson, P. J., Stockwell, W. R., Walcek, C. J., Madronich, S., Middleton, P. B., Pleim, J. E., and Lansford, H. H.: The regional acid deposition model and engineering model, State-ofScience/Technology, Report 4, National Acid Precipitation Assessment Program, Washington DC, USA, 1989.

Colman, J. J., Swanson, A. L., Meinardi, S., Sive, B. C., Blake, D. R., and Rowland, F. S.: Description of the analysis of a wide range of volatile organic compounds in whole air samples collected during PEM-Tropics A and B, Anal. Chem., 73, 37233731, 2001.

Crounse, J. D., DeCarlo, P. F., Blake, D. R., Emmons, L. K., Campos, T. L., Apel, E. C., Clarke, A. D., Weinheimer, A. J., McCabe, D. C., Yokelson, R. J., Jimenez, J. L., and Wennberg, P. O.: Biomass burning and urban air pollution over the Central Mexican Plateau, Atmos. Chem. Phys., 9, 4929-4944, 2009, http://www.atmos-chem-phys.net/9/4929/2009/.

de Foy, B., Varrela, J. R., Molina, L., and Molina, M.: Rapid ventilation of the Mexico City basin and regional fate of the urban plume, Atmos. Chem. Phys., 6, 2321-2335, 2006,

http://www.atmos-chem-phys.net/6/2321/2006/.

de Gouw, J. A., Goldan, P. D., Warneke, C., Kuster, W. C., Roberts, J. M., Marchewka, M., Bertman, S. B., Pszenny, A. A., and Keene, W. C.: Validation of proton-transfer reactionmass spectrometry (PTR-MS) measurements of gas-phase organic compounds in the atmosphere during the New England Air Quality Study (NEAQS), J. Geophys. Res., 108, doi:10.1029/2003JD003863, 2003, 2002.

de Gouw, J., Warneke, C., Karl, T., Eerdekens, G., Van der Veen, C., and Fall, R.: Sensitivity and specificity of atmospheric trace gas detection by proton-transfer-reaction mass spectrometry, Int. J. Mass Spect., 223-224, 365-382, 2003.

de Gouw, J. A., Middlebrook, A. M., Warneke, C., et al.: Budget of organic carbon in a polluted atmosphere: Results from the New England Air Quality Study in 2002, J. Geophys. Res., 110, D16305, doi:10.1029/2004JD005623, 2005.

de Gouw, J. and Warneke, C.: Measurements of volatile organic compounds in the earth's atmosphere using proton-transferreaction mass spectrometry, Mass Spectrom. Rev., 26, 223-257, 2007.

de Gouw, J. A., Welsh-Bon, D., Warneke, C., Kuster, W. C., Alexander, L., Baker, A. K., Beyersdorf, A. J., Blake, D. R., Canagaratna, M., Celada, A. T., Huey, L. G., Junkermann, W., Onasch, T. B., Salcido, A., Sjostedt, S. J., Sullivan, A. P., Tanner, D. J., Vargas, O., Weber, R. J., Worsnop, D. R., Yu, X. Y., and Zaveri, R.: Emission and chemistry of organic carbon in the gas and aerosol phase at a sub-urban site near Mexico City in March 2006 during the MILAGRO study, Atmos. Chem. Phys., 9, 3425-3442, 2009,

http://www.atmos-chem-phys.net/9/3425/2009/.

Doskey, P. V., Porter J. A., and Scheff, P. A.: Source fingerprints for volatile non-methane hydrocarbons, J. Air Waste Manag. Assoc. 42, 1437-1445, 1992.

Emmons, L. K., Walters, S., Hess, P. G., Lamarque, J.-F., Pfister, G. G., Fillmore, D., Granier, C., Guenther, A., Kinnison, D., Laepple, T., Orlando, J., Tie, X., Tyndall, G., Wiedinmyer, C., Baughcum, S. L., and Kloster, S.: Description and evaluation of the Model for Ozone and Related chemical Tracers, version 4 (MOZART-4), Geosci. Model Dev., 3, 43-67, 2010 a.
Emmons, L. K., Apel, E. C., Lamarque, J.-F., et al.: Impact of Mexico City emissions on regional air quality from MOZART-4 simulations, Atmos. Chem. Phys. Discuss., 10, 3457-3498, 2010b, http://www.atmos-chem-phys-discuss.net/10/3457/2010/.

Fast, J. D., de Foy, B., Acevedo Rosas, F., Caetano, E., Carmichael, G., Emmons, L., McKenna, D., Mena, M., Skamarock, W., Tie, X., Coulter, R. L., Barnard, J. C., Wiedinmyer, C., and Madronich, S.: A meteorological overview of the MILAGRO field campaigns, Atmos. Chem. Phys., 7, 2233-2257, 2007, http://www.atmos-chem-phys.net/7/2233/2007/.

Fast, J. D.: Evaluating simulated primary anthropogenic and biomass burning organic aerosols during MILAGRO: implications for assessing treatments of secondary organic aerosols, Atmospheric Chemistry and Physics Discussions, 9, 4805-4871, 2009.

Fortner, E. C., Zheng, J., Zhang, R., Berk Knighton, W., Volkamer, R. M., Sheehy, P., Molina, L., and André, M.: Measurements of Volatile Organic Compounds Using Proton Transfer Reaction - Mass Spectrometry during the MILAGRO 2006 Campaign, Atmos. Chem. Phys., 9, 467-481, 2009, http://www.atmos-chem-phys.net/9/467/2009/.

Fried, A. Weibring, P., Walega, J., et al.: Detailed Comparisons of Airborne Tunable Diode Laser Absorption Spectroscopy Measurements of Formaldehyde with Box Model Calculations during the 2006 INTEX-B Campaign over Mexico, the Gulf of Mexico and the Remote Pacific Ocean, in preparation, Atmos. Chem, Phys., 2010.

Galbally, I. E. and Kirstine, W.: The production of methanol by flowering plants and the global cycle of methanol, J. Atmos. Chem., 43, 195-229, 2002.

Garcia, A. R., Volkamer, R., Molina, L. T., Molina, M. J., Samuelson, J., Mellqvist, J., Galle, B., Herndon, S. C., and Kolb, C. E.: Separation of emitted and photochemical formaldehyde in Mexico City using a statistical analysis and a new pair of gas-phase tracers, Atmos. Chem. Phys., 6, 4545-4557, 2006, http://www.atmos-chem-phys.net/6/4545/2006/.

Gelencsér, A., Siszler, K., and Hlavay, J.: Toluene-benzene concentration ratio as a tool for characterizing the distance from vehicular emission sources, Environ. Sci. Technol., 31, 2869-2872, 1997.

Granier, C. et al.: Present and future surface emissions of atmospheric compounds, European Commission report EVK 2199900011, http://www.aero.jussieu.fr/projet/ACCENT/POET. php, 2004.

Grell, G. A., Peckham, S. E., Schmitz, R., McKeen, S. A., Wilczak, J., and B. Eder, Fully coupled "online" chemistry within the WRF model, Atmos. Environ. 39, 6957-6975, 2005.

Grutter, M., Flores, E., Andraca-Ayala, G., and Baez, A.: Formaldehyde levels in downtown Mexico City during 2003, Atmos. Environ., 39, 1027-1034, 2005.

Hak, C., Pundt, I., Trick, S., Kern, C., Platt, U., Dommen, J., Ordóñez, C., Prévôt, A. S. H., Junkermann, W., AstorgaLloréns, C., Larsen, B. R., Mellqvist, J., Strandberg, A., Yu, Y., Galle, B., Kleffmann, J., Lörzer, J. C., Braathen, G. O., and Volkamer, R.: Intercomparison of four different in-situ techniques for ambient formaldehyde measurements in urban air, Atmos. Chem. Phys., 5, 2881-2900, 2005, http://www.atmos-chem-phys.net/5/2881/2005/.

Heikes, B. G., Chang, W., Pilson, M. E. Q., Swift, E., Singh, H. 
B., Guenther, A., Jacob, D. J., Field, B. D., Fall, R., Riemer, D., and Brand, L.: Atmospheric Methanol Budget and Ocean Implications, Global Biogeochem. Cy., 16(80), 1-13, 2002.

Jacob, D. J., Crawford, J. H., Kleb, M. M., Connors, V. S., Bendura, R. J., Raper, J. L., Sachse, G. W., Gille, J. C., Emmons, L., and Heald, C. L.: The Transport and Chemical Evolution over the Pacific (TRACE-P) aircraft mission: design, execution, and first results, J. Geophys. Res., 108, 9000, doi:10.1029/2002JD003276, 2003.

Junkermann W. and Burger, J. M.: A new portable instrument for continuous measurement of formaldehyde in ambient air, J. Atmos. Ocean. Technol., 23, 38-45, 2006.

Karl, T., Apel, E., Hodzic, A., Riemer, D. D., Blake, D. R., and Wiedinmyer, C.: Emissions of volatile organic compounds inferred from airborne flux measurements over a megacity, Atmos. Chem. Phys., 9, 271-285, 2009.

Lei, W., Zavala, M., de Foy, B., Volkamer, R., and Molina, L. T.: Characterizing ozone production and response under different meteorological conditions in Mexico City Atmos. Chem. Phys., 8, 7571-7581, 2008,

http://www.atmos-chem-phys.net/8/7571/2008/.

Lei, W., de Foy, B., Zavala, M., Volkamer, R., and Molina, L. T., Characterizing ozone production in the Mexico City Metropolitan Area: a case study using a chemical transport model, Atmos. Chem. Phys., 7, 1347-1366, 2007,

http://www.atmos-chem-phys.net/7/1347/2007/.

Lei, W., Zavala, M., de Foy, B., Volkamer, R., Molina, M. J., and Molina, L. T.:Impact of primary formaldehyde on air pollution in the Mexico City Metropolitan Area, Atmos. Chem. Phys., 9, 2607-2618, 2009,

http://www.atmos-chem-phys.net/9/2607/2009/.

Lin, X., Trainer, M., and Liu, S. C.: On the nonlinearity of the tropospheric ozone production, J. Geophys. Res., 93(D12), 1587915888, doi:10.1029/88JD03750, 1988.

Lindinger, W., Hansel, A., and Jordan, A.: Proton transfer reactionmass spectrometry (PTR-MS): on-line monitoring of volatile organic compounds at pptv levels, Chem. Soc. Rev., 27, 347-354, 1998.

Madronich, S. and Flocke, S.: The role of solar radiation in atmospheric chemistry, in Handbook of Environmental Chemistry, edited by: Boule, P., Springer-Verlag, Heidelberg, Germany, 126, 1999.

Madronich, S.: Chemical evolution of gaseous air pollutants downwind of tropical megacities: Mexico City case study, Atmos. Environ., 40, 6012-6018, 2006.

McKeen, S., Liu, S., Hsie, E.-Y., Lin, X., Bradshaw, J., Smyth, S., Gregory, G., and Blake, D.: Hydrocarbon ratios during PEM West A: a model perspective, J. Geophys. Res., 101D, 15, 20872109, 1996.

Mena-Carrasco, M., Carmichael, G. R., Campbell, J. E., Zimmerman, D., Tang, Y., Adhikary, B., D'allura, A., Molina, L. T., Zavala, M., Garca, A., Flocke, F., Campos, T., Weinheimer, A. J., Shetter, R., Apel, E., Montzka, D. D., Knapp, D. J., and Zheng, W.: Assessing the regional impacts of Mexico City emissions on air quality and chemistry, Atmos. Chem. Phys., 9, 3731-3743, 2009, http://www.atmos-chem-phys.net/9/3731/2009/.

Millet, D. B., Jacob, D. J., Custer, T. G., de Gouw, J. A., Goldstein, A. H., Karl, T., Singh, H. B., Sive, B. C., Talbot, R. W., Warneke, C., and Williams, J.: New constraints on terrestrial and oceanic sources of atmospheric methanol, Atmos. Chem. Phys., 8, 6887-6905, 2008,

http://www.atmos-chem-phys.net/8/6887/2008/.

Molina, L. and Molina, M. (Eds.): Air Quality in the Mexico MegaCity: An Integrated Assessment, Kluwer Academic Publishers, Dordrecht, The Netherlands, 384 pp., 2002.

Molina, L., E., de Foy, B., Fast, J., et al.: An Overview of the MILAGRO 2006 Campaign: Mexico City Emissions and their Transport and Transformation, submitted, Atmos. Chem Phys. Discuss., submitted, 2010.

Molina, L. T., Madronich, S., Gaffney, J. S., and Singh, H. B.: Overview of MILAGRO/INTEX-B Campaign, IGAC Newsletter, 38, 2-15, 2008.

Ortega, J., Karl, T., Kleinman, L., et al.: Intercomparison of inflight VOC concentrations using proton transfer mass spectrometry (PTR-MS) during the MILAGRO Campaign (March 2006): Battelle G-1 vs. NCAR C-130 coordinated flights, First MILAGRO Science Meeting, 2006.

Parrish, D. D., Trainer, M., Holloway, J. S., Yee, J. E., Warshawsky, M. S., Fehsenfeld, F. C., Forbes, G. L., and Moody, J. L.: Relationships between ozone and carbon monoxide at surface sites in the North Atlantic region, J. Geophys. Res., 103, 20, 1335713376, 1998.

Parrish, D. D., Dunlea, E., Atlas, E., Schauffler, S., Donnelly, S., Stroud, V., Goldstein, A., Millet, D., McKay, M., Jaffe, D., Price, H., Hess, P., Flocke, F., and Roberts, J.: Changes in the photochemical environment of the temperate North Pacific troposphere in response to increased Asian emissions, J. Geophys. Res. 109, D23S18, doi:10.1029/2004JD004978, 2004.

Seila, R. L., Lonneman, W. A., and Meeks, S. A.: Determination of $\mathrm{C}_{2}$ to $\mathrm{C}_{12}$ ambient air hydrocarbons in 39 U.S. cities, from 1984 through 1986, project summary, US Environ. Prot. Agency, Washington DC, USA, 418 pp., 1989.

Singh, H. B., Kanakidou, M., Crutzen, P. J., and Jacob, D. J.: High concentrations and photochemical fate of oxygenated hydrocarbons in the global troposphere, Nature, 378, 50-54, 1995.

Stroud, C. A., Morneau, G., Makar, P. A., Moran, M. D., Gong, W., Pabla, B., Zhang, J., Bouchet, V. S., Fox, D., Venkatesh, S., Wang, D., and Dann, T.: OH-reactivity of volatile organic compounds at urban and rural sites across Canada: Evaluation of air quality model predictions using speciated VOC measurements, Atmos. Env., 42, 7746-7756, 2008.

Roberts, J., Fehsenfeld, F., Liu, S., Bollinger, M., Hahn, C., Albritton, D., and Sievers, R.: Measurements of aromatic hydrocarbon ratios and $\mathrm{NO}_{\mathrm{x}}$ concentrations in the rural troposphere: observation of air mass photochemical aging and $\mathrm{NO}_{\mathrm{x}}$ removal, Atmos. Environ., 18, 2421-2432, 1984.

Rogers, T. M., Grimsrud, E. R., Herndon, S. C., Jayne, J. T., Kolb, C. E., Allwine, E., Westberg, H., Lamb, B. K., Zavala, M., Molina, L. T., Molina, M. J., and Knighton, W. B.: On-road measurements of volatile organic compounds in the Mexico City Metropolitan Area using proton transfer reaction mass spectrometry, Int. J. Mass Spectrom., 252, 26-37, 2006.

Sommariva, R., Osthoff, H. D., Brown, S. S., Bates, T. S., Baynard, T., Coffman, D., de Gouw, J. A., Goldan, P. D., Kuster, W. C., Lerner, B. M., Stark, H., Warneke, C., Williams, E. J., Fehsenfeld, F. C., Ravishankara, A. R., and Trainer, M.: Radicals in the marine boundary layer during NEAQS 2004: a model study of day-time and night-time sources and sinks, Atmos. Chem. Phys., 
9, 3075-3093, 2009,

http://www.atmos-chem-phys.net/9/3075/2009/.

Tie, X., Madronich, S., Walters, S., Rasch, P., and Collins, W.: Effect of Clouds on photolysis and oxidants in the troposphere, J. Geophys. Res., 108, 4642, doi:10.1029/2003JD003659, 2003.

Tie, X. X., Madronich, S., Li, G. H., Ying, Z. M., Zhang, R. Y., Garcia, A. R., Lee-Taylor, J., and Liu, Y. B.: Characterizations of chemical oxidants in Mexico City: A regional chemical dynamical model (WRF-Chem) study, Atmos. Environ., 41, 1989-2008, 2007.

Tie X., Madronich, S., Li, G., Ying, Z., Weinheimer, A., Apel, E., and Campos, T.: Simulation of Mexico City Plumes during the MIRAGE-Mex Field Campaign using the WRF-Chem model, Atmos. Chem. Phys., 9, 4621-4638, 2009,

http://www.atmos-chem-phys.net/9/4621/2009/.

Vega, E., Mugica, V., Carmona, R., and Valencia, E.: Hydrocarbon source apportionment in Mexico City using the chemical mass balance receptor model, Atmos. Environ., 34, 4121-4129, 2000.

Velasco, E., Lamb, B., Pressley, S., Allwine, E., Westberg, H., Jobson, T., Alexander, M., Prazeller, P., Molina, L., and Molina, M.: Flux measurements of volatile organic compounds from an urban landscape, Geophys. Res. Lett., 32, L20802, doi:10.1029/2005GL023356, 2005.

Velasco, E., B. Lamb, H. Westberg, E. Allwine, G. Sosa, J. L. Arriaga-Colina, B. T. Jobson, M. L. Alexander, P. Prazeller, W. B. Knighton, T. M. Rogers, M. Grutter, S. C. Herndon, C. E. Kolb, M. Zavala, B. de Foy, R. Volkamer, L. T. Molina, and M. J. Molina Distribution, magnitudes, reactivities, ratios and diurnal patterns of volatile organic compounds in the Valley of Mexico during the MCMA 2002 \& 2003 field campaigns, Atmos. Chem. Phys., 7, 329-353, 2007, http://www.atmos-chem-phys.net/7/329/2007/.

Volkamer, R., Molina, L. T., Molina, M. J., Shirley, T., and Brune, W. H.: DOAS measurement of glyoxal as an indicator for fast VOC chemistry in urban air, Geophys. Res. Lett., 32, L08806, doi:10.1029/2005GL022616, 2005.

Volkamer, R., San Martini, F., Salcedo, D., Molina, L. T., Jimenez, J. L., and Molina, M. J.: A Missing Sink for Gas-Phase Glyoxal in Mexico City: Formation of Secondary Organic Aerosol, Geophys. Res. Lett., 34, L19807, doi:10.1029/2007GL030752, 2007

Voss, P. B., Zaveri, R. A., Flocke, F. M., Mao, H., Hartley, T. P., DeAmicis, P., Deonandan, I., Contreras-Jiménez, G., MartnezAntonio, O., Figueroa Estrada, M., Greenberg, D., Campos, T. L., Weinheimer, A. J., Knapp, D. J., Montzka, D. D., Crounse, J. D., Wennberg, P. O., Apel, E., Madronich, S., and de Foy, B.: Long-range pollution transport during the MILAGRO-2006 campaign: a case study of a major Mexico City outflow event using free-floating altitude-controlled balloons, Atmos. Chem. Phys. Discuss., 10, 3347-3399, 2010,

http://www.atmos-chem-phys-discuss.net/10/3347/2010/.

Voss, P., Hartley, T. P., DeAmicis, P., et al.: Reconstruction of trajectories, mixing, and dispersion of a Mexico City pollution outflow event using in-situ observations from free-floating altitudecontrolled balloons, Eos Trans. AGU, 88(52), Fall Meet. Suppl., Abstract A41F-07, 2007.

Warneke, C., McKeen, S. A., de Gouw, J. A., et al.: Determination of urban volatile organic compound emission ratios and comparison with an emissions database, J. Geophys. Res., 112, D10S47,
doi:10.1029/2006JD007930, 2007.

Warneke, C., de Gouw, J. A., Lovejoy, E. R., Murphy, P. C., Kuster, W. C., and Fall, R.: Development of Proton-Transfer Ion Trap-Mass Spectrometry: on-line detection and identification of volatile organic compounds in air, J. Amer.. Soc. M. Spectrom. 16, 1316-1324, 2005a.

Wert, B. P., Trainer, M., Fried, A., et al.: Signatures of terminal alkene oxidation in airborne formaldehyde measurements during TexAQS 2000, J. Geophys. Res., 108, 4104, doi:10.1029/2002JD002502, 2003.

Wesely, M. L.: Parameterization of surface resistance to gaseous dry deposition in regional-scale numerical models, Atmos. Environ. 23, 1293-1304, 1989.

West, J. J., Zavala, M. A., Molina, L. T., Molina, M. J., Martini, F. S., McRae, G. J., Iglesias, G. S., and Colina, J. L.: Modeling ozone photochemistry and evaluation of hydrocarbon emissions in the Mexico City metropolitan area, J. Geophys. Res., 109, D19312, doi:10.1029/2004JD004614, 2004.

Wiedinmyer, C., Quayle, B., Geron, C., Belote, A., McKenzie, D., Zhang, X., O’Neill, S., and Wynne, K.: Estimating emissions from fires in North America for air quality modeling, Atmos. Environ., 40, 3419-3432, 2006.

Wood, E. C., Herndon, S. C., Onasch, T. B., Kroll, J. H., Canagaratna, M. R., Kolb, C. E., Worsnop, D. R., Neuman, J. A., Seila, R., Zavala, M., and Knighton, W. B.: A case study of ozone production, nitrogen oxides, and the radical budget in Mexico City, Atmos. Chem. Phys., 9, 2499-2516, 2009, http://www.atmos-chem-phys.net/9/2499/2009/.

Yokelson, R. B., Urbanski, S. P., Atlas, E. L., Toohey, D. W., Alvarado, E. C., Crounse, J. D., Wennberg, P. O., Fisher, M. E., Wold, C. E., Campos, T. L. Adachi, K., Buseck, P. R., and Hao, W. M., Emissions from forest fires near Mexico City, Atmos. Chem. Phys., 7, 5569-5584, 2007,

http://www.atmos-chem-phys.net/7/5569/2007/.

Zavala, M., Herndon, S. C., Slott, R. S., Dunlea, E. J., Marr, L. C., Shorter, J. H., Zahniser, M., Knighton, W. B., Rogers, T. M., Kolb, C. E., Molina, L. T., and Molina, M. J.: Characterization of on-road vehicle emissions in the Mexico City Metropolitan Area using a mobile laboratory in chase and fleet average measurement modes during the MCMA-2003 field campaign, Atmos. Chem. Phys., 6, 5129-5142, 2006, http://www.atmos-chem-phys.net/6/5129/2006/.

Zhang, Q., Streets, D. G., Carmichael, G. R., He, K. B., Huo, H., Kannari, A., Klimont, Z., Park, I. S., Reddy, S., Fu, J. S., Chen, D., Duan, L., Lei, Y., Wang, L. T., and Yao, Z. L.: Asian emissions in 2006 for the NASA INTEX-B mission, Atmos. Chem. Phys., 9, 5131-5153, 2009a, http://www.atmos-chem-phys.net/9/5131/2009/.

Zhang, Y., Dubey, M. K., Olsen, S. C., Zheng, J., and Zhang, R.: Comparisons of WRF/Chem simulations in Mexico City with ground-based RAMA measurements during the 2006MILAGRO, Atmos. Chem. Phys., 9, 3777-3798, 2009, http://www.atmos-chem-phys.net/9/3777/2009/.

Zhao, J. and Zhang, R. Y.: Proton transfer reaction rate constants between hydronium ion $\left(\mathrm{H}_{3} \mathrm{O}^{(+)}\right)$and volatile organic compounds, Atmos. Environ., 38, 2177-2185, 2004. 